Journal for ImmunoTherapy of Cancer

\title{
Immunosuppressive metabolites in tumoral immune evasion: redundancies, clinical efforts, and pathways forward
}

\author{
Maria Rain Jennings (D) , ${ }^{1}$ David Munn, ${ }^{2}$ John Blazeck (D) ${ }^{1}$
}

To cite: Jennings MR, Munn D, Blazeck J. Immunosuppressive metabolites in tumoral immune evasion: redundancies, clinical efforts, and pathways forward. Journal for ImmunoTherapy of Cancer 2021;9:e003013. doi:10.1136/jitc-2021-003013

Accepted 11 September 2021

Check for updates

(C) Author(s) (or their employer(s)) 2021. Re-use permitted under CC BY-NC. No commercial re-use. See rights and permissions. Published by BMJ.

${ }^{1}$ Chemical and Biomolecular Engineering, Georgia Institute of Technology, Atlanta, Georgia, USA

${ }^{2}$ Medical College of Georgia, Augusta University, Augusta, Georgia, USA

Correspondence to

Dr John Blazeck;

john.blazeck@chbe.gatech.edu

\section{ABSTRACT}

Tumors accumulate metabolites that deactivate infiltrating immune cells and polarize them toward anti-inflammatory phenotypes. We provide a comprehensive review of the complex networks orchestrated by several of the most potent immunosuppressive metabolites, highlighting the impact of adenosine, kynurenines, prostaglandin E2, and norepinephrine and epinephrine, while discussing completed and ongoing clinical efforts to curtail their impact. Retrospective analyses of clinical data have elucidated that their activity is negatively associated with prognosis in diverse cancer indications, though there is a current paucity of approved therapies that disrupt their synthesis or downstream signaling axes. We hypothesize that prior lukewarm results may be attributed to redundancies in each metabolites' synthesis or signaling pathway and highlight routes for how therapeutic development and patient stratification might proceed in the future.

\section{INTRODUCTION}

Tumors exhibit spectacular dexterity in evading immune response. ${ }^{1}$ Cancer cells co-opt immune checkpoints, deactivating immune cells through receptor-ligand interactions and through the production of immunosuppressive metabolic byproducts. Within the last decade, seven checkpoint inhibitor antibodies have been approved by the Food and Drug Administration (FDA) to address suppressive receptor-ligand interactions between tumor and immune cells mediated by cytotoxic T-lymphocyte-associated antigen 4 (CTLA-4), programmed cell death 1 (PD1 ), or programmed death-ligand 1 (PD-L1). ${ }^{2}$ However, there are no therapies for cancer indications that address the activity of immunosuppressive metabolites, despite their contribution to tumorous immunosuppression and negative impact on patient prognosis. The synthesis and signaling pathways of the most potent immunosuppressive metabolites, including adenosine, kynurenine, prostaglandin E2 (PGE2), and norepinephrine and epinephrine are inherently redundant. Several metabolic enzymes or distinct enzymatic pathways might catalyze their synthesis in the tumor microenvironment, and once created, they can agonize multiple receptors on immune cells. We hypothesize that such redundancies have been a key obstacle slowing development of effective pharmacological blockades against these metabolites.

To this end, we will review each immunosuppressive metabolite's synthesis and signaling networks, detailing how internal redundancies may contribute to difficulties developing effective therapeutic interventions. We will also highlight instances of interplay within and between these immunosuppressive networks that might be considered in future clinical and preclinical efforts. Finally, we will discuss several potential pathways forward, emphasizing broad-acting therapeutics, combination therapies, and biomarkerbased patient stratification. We note that the immunosuppressive metabolites discussed here are not an exhaustive representation of those that can be found in the tumor. Other immunosuppressive metabolites like lactate and downstream catabolites of arginine, including nitric oxide and polyamines, have been reviewed elsewhere. ${ }^{3-6}$

\section{SYNTHESIS OF IMMUNOSUPPRESSIVE METABOLITES}

In addition to mediating immune escape in cancer, adenosine, kynurenines, PGE2, and norepinephrine and epinephrine have varied and widespread physiological roles, which may explain why redundant generation mechanisms exist for each. To wit, adenosine is an intermediate in nucleotide recycling that regulates sleep and influences cardiovascular plasticity. ${ }^{7}$ Regulation of the kynurenine pathway is essential to normal cerebral function, and its dysregulation has been linked to neurobiological and psychological diseases. ${ }^{8}$ PGE2 influences hematopoiesis, neuronal signaling, and renal function, 
and norepinephrine and epinephrine (ie, epinephrine) are the classical "fight-or-flight" hormones. ${ }^{910}$

\section{Adenosine: redundant enzymes and distinct biosynthetic pathways}

Adenosine is a ubiquitous nucleoside that is primarily generated in the extracellular space. Normal levels are between 40 and $460 \mathrm{nM}$, but tumorous concentrations can reach $1-100 \mathrm{uM}^{11-13}$ In addition to cancer cells, several immune cells can synthesize adenosine, particularly tumor-resident Tregs, myeloid-derived suppressor cells (MDSCs), and tumor-associated macrophages (TAMs). ${ }^{14}$ Multiple metabolic pathways, each of which can employ multiple enzyme homologs, can produce adenosine.

The most studied pathway has two steps: hydrolysis of ATP to AMP via an ectonucleoside triphosphate diphosphohydrolase (ENTPDase), and then hydrolysis of AMP to adenosine by a 5'-nucleotidase ( $5^{\prime}$ NTDase). The hypoxic tumor microenvironment promotes ATP release into the extracellular space by stressed, dead and dying cells, ensuring substrate availability. The membrane-anchored enzymes CD39 (ENTPDase) and CD73 (5'NTDase) have been broadly implicated in cancer and can be upregulated on cancer and immune cells, though numerous other ectoenzymes catalyze hydrolysis of ATP or AMP (figure 1). ${ }^{1415}$ For example, alkaline phosphatases hydrolyze AMP into adenosine and are upregulated in certain cancers. ${ }^{16} 17$

Adenosine can also be synthesized from nicotinamide adenine dinucleotide $\left(\mathrm{NAD}^{+}\right)$in two related extracellular metabolic pathways. In one, CD203a degrades $\mathrm{NAD}^{+}$ into nicotinamide mononucleotide and AMP, and in the other, CD38 converts $\mathrm{NAD}^{+}$into nicotinamide and ADP ribose, which is then cleaved by CD203a into pyrophosphate and AMP. ${ }^{18}$ AMP can then be dephosphorylated into adenosine by a 5'NTDase, an AP, or the tartrateresistant acid phosphatase enzyme. ${ }^{19}$ Connexin 43 allows for intracellular $\mathrm{NAD}^{+}$to traverse the cell membrane. ${ }^{20}$

Similarly, adenosine can be synthesized from cyclic AMP (cAMP) through two metabolic pathways (figure 1). In one, 10 adenylate cyclase isoforms catalyze the conversion of extracellular ATP to cAMP, and in the other, intracellular cAMP is secreted via the multidrug resistance proteins 4,5 , and $8(\mathrm{MRP} 4,5,8){ }^{21}$ cAMP is converted to AMP through an ectophosphodiesterase (PDE) (likely to be an isoform from one of the PDE super families 4,7,8,10,11), and AMP is dephosphorylated into adenosine. ${ }^{22}$ Extracellular AMP may instead be deaminated by AMP deaminase to form inosine monophosphate, which can be dephosphorylated by CD73 to form inosine. ${ }^{23}$ Adenosine deamination, catalyzed by either adenosine deaminase (ADA) 1 or 2 , also yields inosine. ${ }^{24}$

Adenosine synthesis can occur through multiple distinct pathways, in which each enzymatic step can be catalyzed by multiple enzymes. While the relative contribution of each pathway or enzyme is currently unknown, this 'synthesis redundancy' could make inhibiting tumorous production of adenosine a challenge.
Kynurenines: indoleamine 2,3-dioxygenase and tryptophan 2,3-dioxygenase redundancies

Ninety-five per cent of the essential amino acid tryptophan is catabolized through the kynurenine pathway (figure 1). ${ }^{25}$ Tumorous metabolic reprogramming upregulates expression of the initial and rate limiting step of the kynurenine pathway, the oxidation of tryptophan to $\mathrm{N}$-formyl L-kynurenine, skewing the pathways' outputs toward production and secretion of kynurenine. ${ }^{26}$ Tryptophan oxidation is catalyzed by any of three distinct enzymes, all of which promote cancer progression and correlate with poor patient outcomes: (1) interferon $\gamma$ (IFN- $\gamma$ )-induced indoleamine 2,3-dioxygenase (IDO1), which is normally expressed in the peripheral lymph organs, colon, and epididymis; (2) IDO2, a less catalytically active isoform of IDO1, that is partly induced by IFN- $\gamma$ and is normally expressed by some antigen-expressing cells, and cells of the liver, kidney, and brain; or (3) tryptophan 2,3-dioxygenase (TDO), an enzyme normally only present in the liver and brain. ${ }^{27-30}$

Formamidases then rapidly convert $\mathrm{N}$-formyl L-kynurenine to kynurenine, which, in normal tissue, can proceed through intermediates before yielding the end products xanthurenic acid, and to a much lesser extent, $\mathrm{NAD}^{+}$(figure 1). ${ }^{31}{ }^{32}$ However, cancer and other cells in the inflammatory tumor environment secrete kynurenine into the extracellular space via the L-type/large neutral amino acid transporter 1 (LAT1) tryptophan/kynurenine antiporter and other transporters, where it can then be imported into T cells by LAT1, LAT2, or Proton-Coupled Amino Acid Transporter 4 (figure 2). ${ }^{33-35}$ Normal serum kynurenine levels are between $\sim 1$ and $3 \mathrm{uM} .{ }^{34}$ While few measurements of kynurenine levels in the tumor microenvironment have been performed, concentrations surpassing $\sim 37 \mathrm{uM}$ have been measured in glioblastoma cell culture supernatant. ${ }^{34}{ }^{36}$ MDSCs, TAMs, neutrophils, endothelial cells, mesenchymal stem cells, and dendritic cells (DCs) can also secrete kynurenine. ${ }^{26}$

A metabolomic and transcriptomic analysis of 928 cell lines in the Cancer Cell Line Encyclopedia revealed that IDO1, IDO2, and TDO mRNA expressions levels are predictive of a cancer cell's ability to produce and secrete kynurenine. ${ }^{37}$ Of the cell lines that highly secreted kynurenine, roughly one-third expressed both IDO1 and TDO, one third expressed only IDO1, and one third only TDO, a heterogeneous expression pattern that was confirmed by transcriptomic data in The Cancer Genome Atlas (TCGA). Such heterogeneity could imply difficulty toward inhibiting only one enzyme as a method to prevent kynurenine synthesis.

Kynurenic acid, another potential immunosuppressive metabolite, is produced through the transamination of kynurenine by four kynurenine aminotransferases (KATs 1-4; figure 1). ${ }^{38}$ All four KATs have been shown to be upregulated in solid and blood cancers, and urine kynurenic acid level is a biomarker for prostate cancer. ${ }^{38}{ }^{39}$ Quinolinic acid, another immunosuppressive metabolite, is a downstream metabolite of kynurenine 


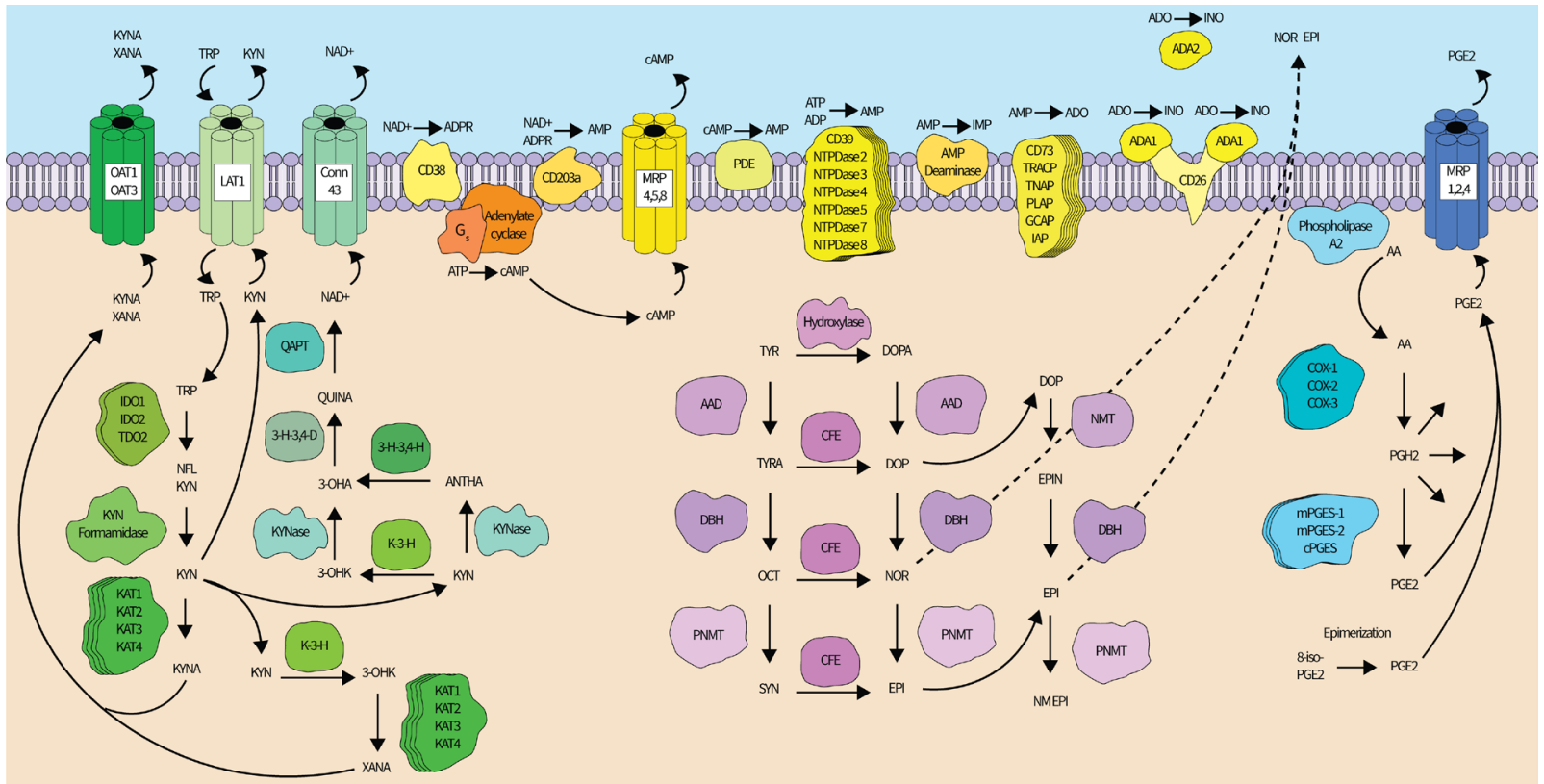

Figure 1 The redundant synthesis networks of immunosuppressive metabolites. Kynurenine pathway (left-green). After being imported into a cell by amino acid transporters, tryptophan is oxidized by one of three enzymes - IDO1, IDO2, or TDO2 - to nformyl-L-kynurenine, which is then converted to kynurenine by formamidases. Kynurenine may exit the cell through the LAT1, which simultaneously imports tryptophan, or continue down the kynurenine pathway until converted into xanthurenic acid (XANA) (major route) or nicotinamide adenine dinucleotide (NAD ${ }^{+}$(minor route). Four different kynurenine aminotransferase (KAT) enzymes can transaminate kynurenine into kynurenic acid. Alternatively, kynurenine can be converted into 3-hydroxy-kynurenine by kynurenine 3-hydroxylase $(\mathrm{K}-3-\mathrm{H})$, or into anthranilic acid by kynureninase. 3-hydroxy-kynurenine may be converted to XANA (by KATs) or 3-hydroxyanthranilic acid (3-OHA) by kynureninase. 3-OHA may also be produced from anthranilic acid by 3-hydroxyanthranilic acid 3,4-hydroxylase (3H-3,4-H). 3-OHA is converted into quinolinic acid by 3-hydroxyanthranilic acid 3,4-dioxygenase $(3 \mathrm{H}-3,4-\mathrm{D})$, and quinolinic acid phosphoribosyl transferase mediates the conversion of quinolinic acid to NAD ${ }^{+}$ XANA and kynurenic acid can be transported out of the cell by the OAT1 and OAT3, while connexin 43 allows NAD ${ }^{+}$transport. Adenosine synthesis pathways (top center-yellow): adenosine synthesis occurs extracellularly in the tumor microenvironment and can use either ATP or NAD ${ }^{+}$as a pathway substrate. ATP (or ADP to a lesser extent) can be dephosphorylated by CD39 or 6 other NTPDases into AMP. NAD ${ }^{+}$can be converted to AMP directly by CD203a or through an ADP ribose (ADPR) intermediate by CD38 (followed by conversion to AMP by CD203a). AMP can also be generated from cAMP. cAMP is synthesized from protein $\mathrm{G}_{\mathrm{s}}$-activated adenylate cyclase from ATP. Intracellular cAMP can be excreted through multidrug resistance proteins 4,5 , or 8 into the extracellular space where a family of ecto-phosphodiesterases convert cAMP into AMP. AMP is finally dephosphorylated to adenosine by six possible enzymes, most prominently CD73. Adenosine can be deaminated to produce inosine by adenosine deaminase 1 (ADA) (membrane-attached via CD26) or 2. AMP can also be deaminated into IMP by AMP deaminase, and IMP can be dephosphorylated by CD73 to generate inosine (not shown). (Nor)epinephrine synthesis pathways (bottom center-magenta): schematic adapted from Molinoff and Axelrod. Epinephrine synthesis begins with tyrosine (TYR) and typically proceeds through L-dopa, dopamine (DOP), and norepinephrine (NOR) intermediates, though a parallel biosynthetic pathway exits. (Nor)epinephrine are exported through an undetermined mechanism. Prostaglandin E2 synthesis pathways (right-Blue): phospholipase A2s cleave AA from the inner leaflet of the cell membrane. Free AA is converted to PGH2 by the cyclooxygenase enzymes (COX-1, COX-2, and in the brain, COX-3). PGH2 is then converted to PGE2 by mPGES-1, mPGES-2, or cPGES (or p23), though PGH2 is also a precursor for several other prostaglandin derivatives (indicated by multiple reaction arrows stemming from PGH2 into the cytosol). PGE2 can also be generated when 8-iso-PGE2 undergoes epimerization. PGE2 is exported by MRP 1, MRP 2, or MRP 4. All proteins are denoted by text within shapes while metabolites are free-floating text. Straight lines indicate an enzyme catalyzed reaction, curved lines indicate transport or are drawn for clarity, and curved dotted lines indicate an undetermined transport mechanism. Stacked proteins indicate the existence of more than one enzyme capable of performing the indicated metabolic reaction. Up to 19 phospholipase enzymes exist in mammals, but only 1 is shown for clarity. 3-OHK, 3-hydroxykynurenine; AA, arachidonic acid; AAD, aromatic acid decarboxylase; ADO, adenosine; ANTHA, anthranilic acid; cAMP, cyclic AMP; CD, cluster of differentiation; CFE, catecholamine-forming enzyme; cPGES, cytosolic prostaglandin E synthase; DBH, dopamine-beta-hydroxylase; EPI, epinephrine; GCAP, germ cell alkaline phosphatase; IDO, indoleamine 2,3-dioxygenase; IAP, intestinal alkaline phosphatase; IMP, inosine monophosphate; INO, inosine; KYNA, kynurenic acid; KYN, kynurenine; KYNase, kynureninase; LAT, L-type/large neutral amino acid transporter; mPGES, microsomal PGE synthase; MRP, multidrug resistance-associated protein; NFL KYN, N-formyl-L-KYN; NM EPI, N-methyl epinephrine; NMT, non-specific methyltransferase; NTPDase, ectonucleoside triphosphate diphosphohydrolase; OAT, organic ion transporter; OCT, octopamine; PDE, phosphodiesterase; PGH2, prostaglandin H2; PLAP, placental alkaline phosphatase; PNMT, phenylethanolamine-N-methyltransferase; QAPT, quinolinic acid phosphoribosyl transferase; QUINA, quinolinic acid; SYN, synephrine; TDO, tryptophan 2,3-dioxygenase; TNAP, tissue-non-specific alkaline phosphatase; TRACP, tartrate-resistant acid phosphatase; TRP, tryptophan; TYRA, tyramine. 


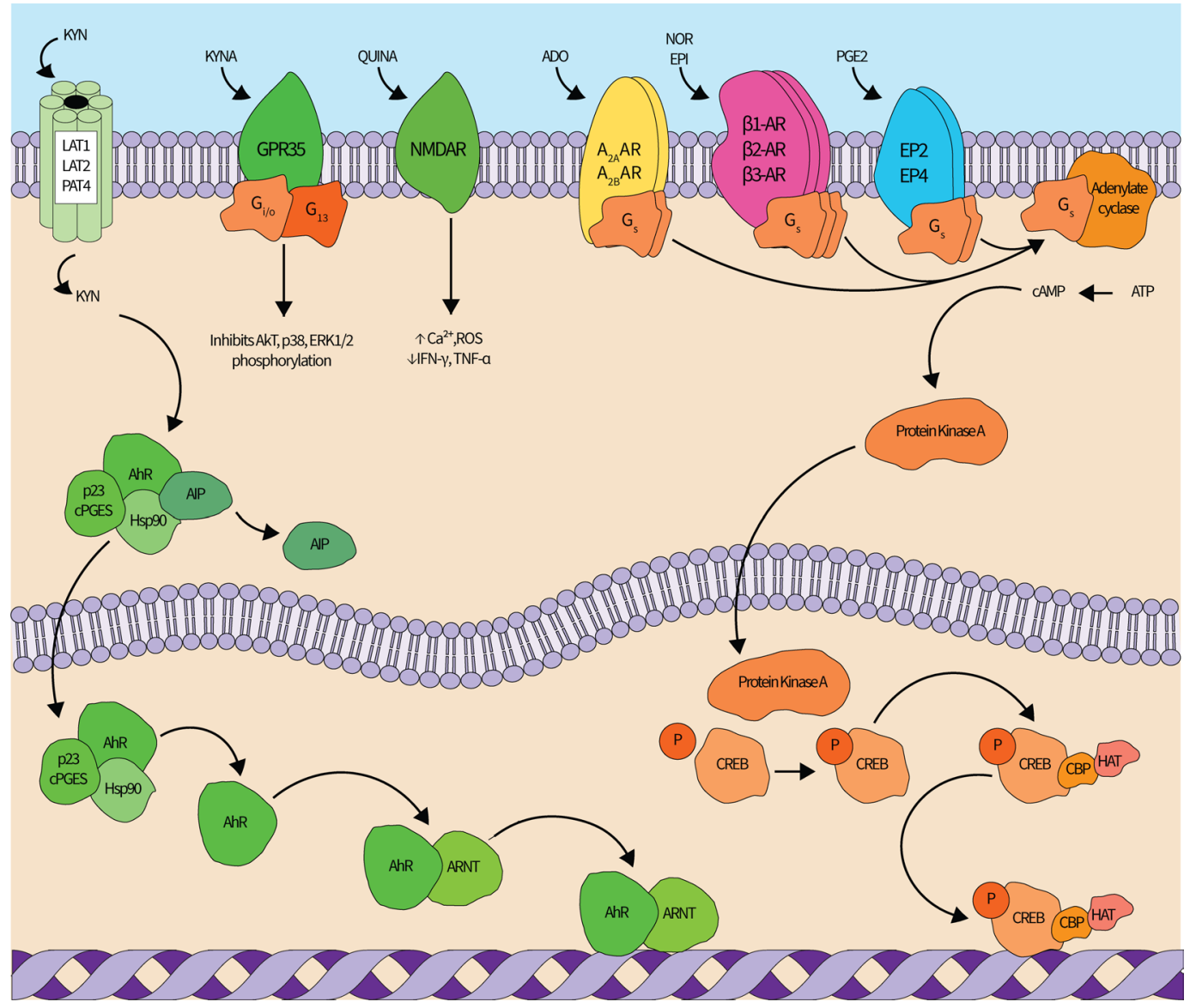

Figure 2 The redundant signaling networks of immunosuppressive metabolites. Kynurenine (KYN) pathway (left-green): KYN enters the cell via the LAT1, LAT2 or PAT4 transporters. In the cytoplasm, KYN binds the AhR-cPGES-Hsp90-AIP complex. AIP dissociates from the complex after KYN binds, and the KYN-AhR-cPGES-Hsp90 complex translocates into the nucleus. within the nucleus, CPGES and Hsp90 dissociate, and AhR forms a heterodimer with Arnt that modulates gene expression in a widespread manner. Kynurenic acid (KYNA) also agonizes the extracellular GPR35 receptor, which inhibits Akt, p38, and ERK1/2 phosphorylation, and quinolinic acid (QUINA) agonizes the NMDA receptors to increase intracellular $\mathrm{Ca}^{2+}$ and $\mathrm{ROS}$ and decrease IFN- $\gamma$ and TNF- $\alpha$ production. Adenosine (ADO) (top center left-yellow): ADO can agonize four different G-protein coupled receptors (GPR35), of which $A_{2 A} A R$ and $A_{2 B} A R$ stimulate cAMP generation and downstream immunosuppression mediated by the CAMP-PKA-CREB pathway, shown in orange. (Nor)epinephrine (NOR) (top center right-magenta): NOR and epinephrine (EPI) can agonize either $\alpha$-adrenergic or $\beta$-adrenergic receptors ( $\beta$-AR). Agonism of all three $\beta$-AR elicits immunosuppressive signaling cascades through cAMP-PKA-CREB. Prostaglandin E2 (PGE2) (top rightadrenergic-blue): similar to ADO, PGE2 can agonize four receptors, of which two (EP2 and EP4) elicit immunosuppressive signaling cascades through CAMP-PKA-CREB. CAMP-PKA-CREB signaling pathway: CAMP production is increased by ADO, NOR, and/or PGE2 signaling through $\mathrm{G}_{\mathrm{s}}$-mediated activation of adenylate cyclase. adenylate cyclase generates cAMP from ATP, and cAMP then activates PKA. A cAMP-PKA complex enters the nucleus where it phosphorylates the CREB transcription factor. phosphorylated CREB recruits HAT and CBP and then modulates target gene expression. All proteins are denoted by text within shapes while metabolites are free-floating text. Straight lines indicate an enzyme catalyzed reaction while curved lines indicate transport or are included for clarity. AxAR, adenosine receptor; AhR, aryl hydrocarbon receptor; AIP, aryl hydrocarbon receptorinteracting protein; ARNT, aryl hydrocarbon receptor nuclear translocator; $\mathrm{Ca}^{2+}$, calcium ion; cAMP, cyclic AMP; CBP, CREB binding protein; CPGES, cytosolic PGE synthase; CREB, CAMP-response element binding protein; EP ${ }_{x}, P G E 2$ receptor; ERK, extracellular signal-regulated kinase; $G_{x}$, protein G; HAT, histone acetyltransferase; Hsp, heat shock protein; IFN- $\gamma$, interferon gamma; LAT, L-type/large neutral amino acid transporter; NMDAR, N-Methyl-D-aspartate receptor; P, phosphate group; PAT, proton-assisted amino acid transporter; ROS, reactive oxidative species; TNF- $\alpha$, tumor necrosis factor alpha.

hydroxylation and can be converted into $\mathrm{NAD}^{+} .{ }^{40}$ Under inflammatory conditions, macrophages and DCs produce quinolinic acid in excess, although the consequences of such are not well understood. ${ }^{40}$ Hydroxylated kynurenine is also converted into xanthurenic acid by a KAT, and xanthurenic and kynurenic acid can be excreted by organic ion transporters 1 and 3, then filtered from the blood in the kidneys. ${ }^{41}{ }^{42}$ In addition to feeding the kynurenine pathway, tryptophan is the metabolic precursor for serotonin, which may have roles in tumorigenesis and immune modulation. ${ }^{43}{ }^{44} \mathrm{Circu}-$ lating serotonin is largely generated in the intestine, then released into the bloodstream where it is stored by platelets. $^{45}$ 


\section{PGE2: cyclooxygenase and PGE synthesis redundancies}

PGE2 is the most common of the prostaglandins, which are ubiquitously synthesized fatty acid hormones. ${ }^{46}$ In solid tumors, PGE synthesis (PGES) enzymes can be upregulated, leading to tumorous accumulation and a 2-3 fold increase in serum levels. ${ }^{47-49}$ Besides cancer cells, TAMs and tolerogenic DCs produce PGE2 ${ }^{50}$ PGE2 synthesis occurs primarily through the three step cyclooxygenase (COX) pathway: first, arachidonic acid is cleaved from the cellular inner membrane by phospholipase A2 enzymes, then COX enzymes convert arachidonic acid to prostaglandin H2 (PGH2) via a PGG2 intermediate, and finally, prostaglandin synthases isomerize PGH2 to PGE2. ${ }^{51}$ PGE2 is exported into the extracellular space, where it can interact with immune cells, by the MRP1,2,4, which are upregulated in blood and solid cancers. ${ }^{52}$ Notably, PGH2 is also required to produce several other essential prostaglandins and their derivatives. ${ }^{53}$

Multiple enzymes can catalyze each step of the COX pathway for PGE2 biosynthesis (figure 1). As many as 19 phospholipase A2 enzymes have been associated with mammalian PGE2 production. ${ }^{51}$ Two COX isoforms, COX-1 and COX-2, can be expressed by most cells, and COX-3, a COX-1 splice variant that retains the first intron, is expressed in the brain. COX-1 and COX-2 employ identical catalytic mechanisms yet differ in terms of transcriptional regulation and protein sequence, and both are upregulated in a variety of cancers. ${ }^{54} \mathrm{COX}-1$ is expressed constitutively, while COX-2 expression is induced by NF-kB or MAPK after exposure to a variety of cytokines or hypoxia. ${ }^{51}$ An amino acid difference between COX-1 and COX-2 (V509I) has allowed development of selective COX-2 inhibitors, with the goal of circumventing toxicity arising from complete inhibition of prostaglandin synthesis. ${ }^{55}$ In the final step of PGE2 synthesis, three PGES can isomerize PGH2 to PGE2: microsomal PGES-1 (mPGES-1), mPGES-2, and cytosolic PGES (cPGES) ${ }^{51}$ mPGES-1 expression is inducible and often elevated in cancers, while mPGES-2 expression is constant but elevated in gliomas and colorectal cancer. ${ }^{515657}$ cPGES, also referred to as p23, has a role of interest in addition to producing PGE2. It forms a complex with the aryl hydrocarbon receptor (AhR), the transcription factor in the kynurenine signaling pathway (discussed below). ${ }^{58}$ Therefore, each step of the primary route of PGE2 synthesis can be catalyzed by multiple enzymes, such that inhibition of a specific enzyme may not fully prevent PGE2 synthesis.

Finally, evidence exists for an alternative PGE2 synthesis method that does not require enzymes. Specifically, free radical-catalyzed peroxidation of arachidonic acid can form the isoprostane, 8-iso-PGE2. 8-iso-PGE2 can undergo acidor base-catalyzed epimerization to PGE2. ${ }^{59}$

Norepinephrine and epinephrine: parallel metabolic pathways Stress incites the canonical flight-or-fight response during which the tyrosine-derived catecholamines, epinephrine and norepinephrine, are released from the adrenal medulla to interact with adrenergic receptors. ${ }^{10}$ Chronic stress and subsequent (nor) epinephrine production have been linked to poor patient prognosis due to the metabolites' action in promoting tumorigenesis and stifling immune response. ${ }^{60}$ Human neuroblastoma, mammary adenocarcinoma, pancreatic ductal carcinoma, and colon adenocarcinoma cell lines, in addition to certain immune subsets, have been shown to secrete nor(epinephrine) ${ }^{61-64}$ For instance, pancreatic ductal carcinoma cells elevated epinephrine and norepinephrine secretion and increased cellular proliferation after exposure to nicotine, while macrophage, peripheral T cells, Tregs, and neutrophils are capable of norepinephrine secretion. ${ }^{6365-68}$

Canonical biosynthesis of norepinephrine and epinephrine begins with tyrosine, which is converted to 3,4-dihydroxyphenylalanine, then dopamine, norepinephrine, and epinephrine. ${ }^{69}$ However, multiple parallel biosynthetic pathways ensure that the production of norepinephrine and epinephrine can occur despite any single enzyme deletion, as reviewed by Molinoff and Axelrod (figure 1). ${ }^{69}$ For instance, norepinephrine synthesis can occur without a dopamine intermediate, and epinephrine synthesis can occur without norepinephrine.

\section{SIGNALING REDUNDANCIES AND IMMUNOSUPPRESSION}

As it is accepted that cancers engage several immune checkpoints simultaneously, the ability of metabolic intermediates to suppress anticancer immune response is of great interest. Kynurenines, adenosine, PGE2, and norepinephrine and epinephrine can all decrease the activity of cytotoxic T cells, key antitumor effector cells. Interestingly, just as multiple enzymes catalyze the biosynthetic pathways to produce these immunosuppressive metabolites (synthesis redundancy), these molecules often mediate their suppressive impact by agonizing more than one receptor (receptor redundancy). In addition to limiting the activity of immune cells, each of these metabolites promotes tumorigenesis through autocrine or paracrine signaling loops.

\section{Adenosine: immunosuppressive signaling through $A_{2 A} A R$ and $A_{2 B} A R$}

Adenosine promotes tolerance in the tumor environment and inhibits anticancer immune cell activity. Adenosine can agonize four $G$ protein-coupled extracellular receptors, $\mathrm{A}_{1} \mathrm{AR}, \mathrm{A}_{2 \mathrm{~A}} \mathrm{AR}, \mathrm{A}_{2 \mathrm{~B}} \mathrm{AR}$, and $\mathrm{A}_{3} \mathrm{AR} .{ }^{70}$ In particular, agonism of the high affinity $\mathrm{A}_{2 \mathrm{~A}}$ or low affinity $A_{2 B}$ adenosine receptors stimulates production of cAMP from ATP, which acts through Protein Kinase A (PKA) and cAMP-response element binding protein (CREB) to inhibit inflammatory signaling pathways and suppress immune responses (figure 2). Agonism of either $A_{2 A} A R$ or $A_{2 B} A R$ results in immunosuppression, and immune cells upregulate both receptors under hypoxic conditions. For 
instance, in $\mathrm{CD}^{+} \mathrm{T}$ cells, $\mathrm{A}_{2 \mathrm{~A}} \mathrm{AR}$ agonism reduces cytotoxicity, inflammatory cytokine production, and TCRmediated signaling. ${ }^{71} \mathrm{~A}_{2 \mathrm{~A}} \mathrm{AR}$ agonism further inhibits inflammatory cytokine production by neutrophils, macrophages, and DCs, and promotes immunosuppressive macrophage behavior. ${ }^{70} 71$ MDSCs also express $\mathrm{A}_{2 \mathrm{~A}} \mathrm{AR}$ in the tumor, and its agonism results in increased interleukin 10 (IL-10) production. ${ }^{71}$ IL-10 has been shown to behave in a dual role to lessen inflammatory response and drive tumor progression in a tumor-specific and context-specific manner. ${ }^{72}$ Adenosine agonizes the lower affinity $A_{2 B} A R$ receptor with similar effects, diminishing $\mathrm{CD}^{+} \mathrm{T}$ cell inflammatory function, reducing NK cytotoxicity, inhibiting neutrophil superoxide production and oxidative burst, and downregulating expression of nitric oxide synthase while increasing IL-10 production by macrophages. ${ }^{73-77}$

Adenosine signaling through $\mathrm{A}_{2 \mathrm{~A}} \mathrm{AR}$ or $\mathrm{A}_{2 \mathrm{~B}} \mathrm{AR}$ further promotes differentiation of tolerogenic immune cells, while acting as a signaling molecule to help mediate their impact. ${ }^{71}$ Adenosine- $\mathrm{A}_{2 \mathrm{~A}} \mathrm{AR}$ signaling promotes Treg differentiation from $\mathrm{CD} 4^{+} \mathrm{T}$ cells, and Tregs experience a positive feedback loop for adenosine synthesis in which adenosine drives their expression of CD39 (figure 3). ${ }^{78}$ Tregs use adenosine to amplify their immunosuppressive effects on other immune cells even in death, as tumor oxidative stress causes apoptotic Tregs to release and convert excessive amounts to ATP to adenosine. ${ }^{80}$ Adenosine- $\mathrm{A}_{2 \mathrm{~B}} \mathrm{AR}$ signaling promotes DC differentiation to a tolerogenic phenotype that expresses vascular endothelial growth factor (VEGF), IL-10, COX-2, transforming growth factor $\beta$ (TGF- $\beta$ ), and IDO (figure 3). ${ }^{81}$ Finally, adenosine signaling within the tumor microenvironment promotes tumorgenicity, vascularization, and metastasis, for instance, via induction of VEGF and TGF- $\beta$ production by cancer and tumor-associated immune cells. ${ }^{7181}$ Because adenosine agonizes two receptors with similar impact, targeting only one therapeutically may not fully prevent its impact.

In addition to adenosine, cAMP and inosine can have immunomodulatory effects. cAMP-activation of PKA in immune cells can limit cytotoxic and effector functions. ${ }^{82}$ Excreted cAMP serves as an additional feedstock for adenosine generation, which could further agonize $A_{2 \mathrm{~A}}$ ${ }_{\mathrm{B}} \mathrm{AR}$ receptors to promote cAMP production in a positive feedback loop. ${ }^{83}$ Inosine has $\sim 1000$ fold less affinity for $\mathrm{A}_{2 \mathrm{~A}} \mathrm{AR}$ than adenosine, but can still induce suppressive signaling cascades. ${ }^{84} 85$ However, recent studies have shown that glucose-deprived effector $\mathrm{T}$ cells can use inosine as a carbon source, and that inosine enhanced the efficacy of adoptive $\mathrm{T}$ cell transfer and checkpoint blockade in solid tumors. ${ }^{86} 87$ Therefore, more work is necessary to deconvolute the role of inosine in the tumor microenvironment.
Kynurenines signaling through AhR, GPR35, and N-methyl-Daspartate receptor

Extensive studies have established the immunological effects caused by catabolism of tryptophan through the kynurenine pathway. IDO induction and the resultant tryptophan depletion was first demonstrated to cause $\mathrm{T}$ cell anergy through the GCN2-mediated starvation response. ${ }^{88}$ Kynurenine, and to a lesser extent its downstream metabolic and transamination products (eg, 3'-hydroxykynurenine, quinolinic acid, and kynurenic acid) have now been shown to broadly suppress antitumor immune cell function by agonizing the AhR. ${ }^{36} 89$ In addition, kynurenine can undergo a spontaneous chemical conversion to create compounds, dubbed trace-extended aromatic condensation products, that bind AhR with picomolar affinity. ${ }^{90}$

Ligand-free AhR resides in the cytoplasm in complex with AhR-interacting protein (AIP), heat shock protein 90, and cPGES/p23. ${ }^{58}$ On ligand binding, the complex sheds AIP, allowing nuclear translocation. The complex fully dissociates in the nucleus, and AhR binds to the AhR Nuclear Translocator (ARNT) to form a heterodimeric transcription factor (figure 2). AhR/ARNT alters expression of thousands of genes that vary in a cell-type and ligand specific manner. ${ }^{91}$ In particular, the kynurenine-AhR axis inhibits the anticancer activity of $\mathrm{CD}^{+}$and $\mathrm{CD} 4^{+} \mathrm{T}$ cells. Signaling mediated by the kynurenine pathway further limits $\mathrm{CD} 8^{+} \mathrm{T}$ cell production of IL-2, decreases efficacy of CAR-T cell therapies, increases CD8 ${ }^{+} \mathrm{T}$ cell PD- 1 expression, and diminishes the efficacy of $\alpha$-PD-1, $\alpha$-PD-L1, and $\alpha$-CTLA4 treatments (figure 3). ${ }^{35}{ }^{92-94}$ Culturing $\mathrm{CD}^{+} \mathrm{T}$ cells with kynurenine generates $\mathrm{CD} 4^{+}$Fox $3 \mathrm{P}^{+}$Tregs in an $\mathrm{AhR}$ and dose-dependent manner. ${ }^{95}$

Similar to adenosine, kynurenines act to promote tumor survival in addition to inhibiting immune cells. ${ }^{36}$ AhR is highly upregulated in cancers and can play a pivotal role in tumor development by dysregulating proliferation, differentiation, metabolism, apoptosis, and angiogenesis. ${ }^{96}$

Certain immune cells may further drive autocrine / paracrine feedforward loops for AhR signaling. In DCs, IDO expression drives kynurenine production, and AhR activation maintains IDO expression (figure 3). ${ }^{97}$ Similarly, MDSCs produce kynurenine by upregulating IDO expression, and kynurenine-AhR signaling promotes MDSC recruitment and activation. ${ }^{98}$ Kynurenine-AhR signaling induces a suppressive feedforward loop in $\mathrm{CD}^{+} \mathrm{T}$ cells by upregulating transcription of kynurenine importers and increasing AhR expression. ${ }^{35}$

Kynurenic acid, also signals through the AhR to reduce $\mathrm{T}$ cell activity, and separately is thought to agonize the G-coupled protein receptor, GPR35, which is expressed by $\mathrm{T}$ cells and some innate immune cells. ${ }^{89} 9099$ GPR35 agonism inhibits phosphorylation of Akt, p38, and ERK $1 / 2$, which may contribute to immune regulation. ${ }^{38}$ For instance, kynurenic acid agonism of GPR35 reduces IL-4 release by invariant natural killer cells and inhibits tumor necrosis factor- $\alpha$ (TNF- $\alpha)$ secretion by monocytes. ${ }^{89} 100$ 


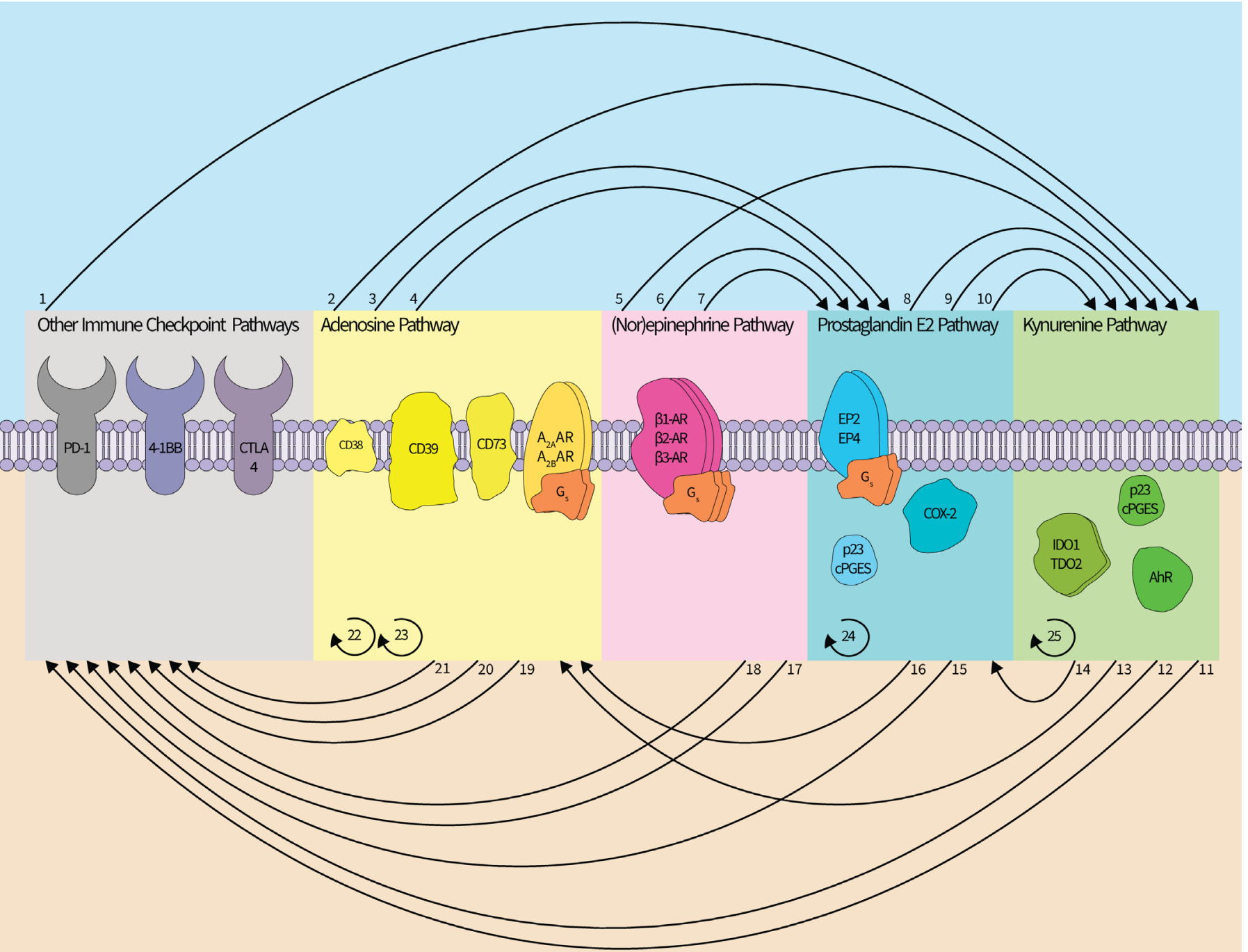

Figure 3 Interactions within and between the immunosuppressive metabolite networks. The adenosine (ADO), kynurenine, (PGE2), (nor)epinephrine (NOR), and other immune checkpoint pathways interact and stimulate each other and may employ feedforward signaling/synthesis regimes. (1) Blockade of PD-1 or CTLA-4 appears to induce (IDO1) expression. (2) $A_{2 B} A R$ signaling induces (IDO1) expression. (3, 4) CD39 and CD73 can promote synthesis of (PGE2), and $A_{2 A} A R$ or $A_{2 B} A R$ signaling can induce expression of COX-2. (5) $\beta$-AR signaling upregulates (IDO1) expression. $(6,7) \beta 2$-AR signaling has been linked to the upregulation of COX-2 and CPGES. $(8,9,10)$ CPGES is a modulator of (AhR) activity, and COX-2 can influence expression of (TDO2) and (IDO1). (11, 12) (AhR) signaling can increase PD-1 expression and correlates with reduced efficacy of an $\alpha C$ CTLA-4 antibody. (13) (AhR) signaling can promote expression of (CD39.) (14) (AhR) signaling can promote expression of COX-2. (15) EP2/4 signaling can increase PD-1 expression. (16) (PGE2) can induce expression of CD73.) $(17,18) \beta$-adrenergic signaling correlates with diminished therapeutic efficacy of $\alpha$ PD-1 antibodies, and decreases the therapeutic efficacy of a 4-1BB blockade. $(19,20)(C D 73)$ expression correlates with diminished therapeutic efficacy of $\alpha P D-1$ antibodies and of an $\alpha C T L A-4$ antibody. (21) CD38 is associated with tumorous resistance to anti-PD-1/PD-L1 antibody therapy. $(22,23) A_{2 A B} A R$ signaling drives (CD73) expression, and $A_{2 A} A R$ signaling increases (CD39) expression. (24) PGE2-EP2/4 signaling can upregulate COX2 expression. (25) (AhR) signaling drives upregulation of (IDO1) expression. In total, direct links between each pathway have been described with the exception of a relationship between ADO and NOR. Colors denoting ADO, kynurenine, (PGE2), and NOR pathways follow (figures 1 and 2). For brevity, the distinct cell types in which these interactions were described are not included. Curved lines between pathways indicate an interpathway interaction whereas curved semicircles indicate intrapathway regulation. $A_{x} A R$, adenosine receptor; $A h R$, aryl hydrocarbon receptor; $\beta$ - $A R, \beta$-adrenergic receptor; $C D$, cluster of differentiation; COX, cyclooxygenase; cPGES, cytosolic prostaglandin E synthase; CTLA, cytotoxic T-lymphocyte-associated protein; EPI, epinephrine; PGE receptorIDO, indoleamine 2,3-dioxygenase; PD, programmed cell death receptor; TDO, tryptophan 2,3-dioxygenase.

Another kynurenine pathway metabolite, quinolinic acid, is a potent agonist of the $N$-methyl-D-aspartate (NMDA) category of glutamate receptors expressed in the central nervous system and on immune subsets. ${ }^{41} 101$ NMDA receptor (NMDAR) agonism leads to increased intracellular $\mathrm{Ca}^{2+}$ and reactive oxidative species concentrations in $\mathrm{T}$ and NK cells, and suppresses the ability of these cells to produce IFN- $\gamma^{102}$ Additionally, activated $\mathrm{CD}^{+} \mathrm{T}$ 
cells upregulate NMDAR expression, and quinolinic acid suppresses their production of IFN- $\gamma$ and TNF- $\alpha .{ }^{103}$

Finally, serotonin is produced from tryptophan in a distinct metabolic pathway, and appears to promote tumor growth or mediate inflammatory signaling in a tumorspecific and context-specific manner. ${ }^{44}$ For instance, serotonin promotes growth of colorectal tumors, but also stimulates the release of IFN- $\gamma$ by lymphocytes and stimulates T cell proliferation. ${ }^{44}{ }^{104}$ It is conceivable that competition for tryptophan precursor could limit either kynurenine or serotonin production.

\section{PGE2 immunosuppressive signaling through EP2 and EP4}

PGE2 can agonize four $\mathrm{G}$ protein-coupled receptors: EP1, EP2, EP3, and EP4. PGE2 signaling through EP2 and EP4 has been implicated in immunosuppression and cancer progression. ${ }^{105}$ EP2 and EP4 agonism results in a downstream increase in intracellular cAMP levels followed by PKA/CREB activation, as seen with adenosine agonism of $A_{2 A} A R$ and $A_{2 B} A R$ (figure 2). ${ }^{106} \mathrm{EP} 2$ is ubiquitously expressed but has lower affinity for PGE2, while EP4 is a high affinity receptor whose expression is induced by hypoxia. ${ }^{9}$

PGE2 signaling through EP2 limits inflammatory T cell responses by interfering with $\mathrm{T}$ cell receptor signaling in $\mathrm{CD}^{+} \mathrm{T}$ cells and by promoting a tolerogenic phenotype in DCs that impairs $\mathrm{CD}^{+} \mathrm{T}$ cell function. ${ }^{107} 108 \mathrm{Simi}-$ larly, EP4 agonism promotes generation of immune cell tolerogenic phenotypes, stimulating differentiation of MDSCSs and Tregs, and immunosuppressive functions by macrophages and neutrophils. ${ }^{109} 110$ In macrophages, EP2 agonism suppresses phagocytosis, enhances IL-10 production, and decreases TNF- $\alpha$ production, and PGE2 upregulates COX-2 expression, in an EP2/4 dependent manner, creating an autocrine feedforward loop (figure 3). ${ }^{111-113}$ Signaling through either EP2 or EP4 results in increased PD-1 expression in tumor-infiltrating $\mathrm{CD}^{+} \mathrm{T}$ cells of lung cancer patients (figure 3 ).${ }^{114}$ Because PGE2-mediated immunosuppression occurs via two receptors, targeting one may not fully prevent its impact. In addition to inhibiting immune responses, PGE2-EP2/ EP4 signaling contributes to tumorigenesis, metastasis, and angiogenesis. ${ }^{105}$

\section{Norepinephrine and epinephrine bind two GPCR classes}

Norepinephrine and epinephrine, often abbreviated (nor)epinephrine hereafter, bind two distinct classes of G-coupled protein receptors: $\alpha$-adrenergic receptors $(\alpha 1$ and $\alpha 2)$ and $\beta$-adrenergic receptors $(\beta 1, \beta 2$, and $\beta 3) .{ }^{115}$ Importantly, agonism of the three $\beta$-adrenergic receptors, all of which can be expressed by immune cells, promotes cAMP production and downstream signaling through the cAMP-PKA-CREB cascade (figure 2). Therefore, it is unsurprising that $\beta$-adrenergic signaling has inhibitory effects on antitumor immunity. While special attention has been paid to the immunoregulatory action of the $\beta 2$-adrenergic receptor, agonism of the $\beta 1$ and $\beta 3$ receptors also suppresses immune cell activity. ${ }^{116}$
For instance, in a murine B-cell lymphoma, non-selective $\beta$-adrenergic $(\beta 1, \beta 2$, and $\beta 3)$ agonism suppressed $\mathrm{CD} 8^{+}$ $\mathrm{T}$ cells, decreasing their proliferation, IFN- $\gamma$ production, and cytotoxicity. ${ }^{117} \beta 2$-adrenergic signaling has also been shown to promote differentiation of $\mathrm{CD}^{+}{ }^{+}$Foxp3 ${ }^{-} \mathrm{T}$ cells into Foxp $3^{+}$Tregs, decrease IL-2 production by $\mathrm{CD} 4^{+} \mathrm{T}$ cells, suppress NK cell cytotoxicity, reduce inflammatory cytokine production by DCs, and increase expression of Arg1 and PD-L1 on tumorous MDSCs. ${ }^{118-122}$ Similarly, $\beta 1$ receptor agonism induces $\mathrm{CD}^{+}$differentiation toward a Treg phenotype, and selective $\beta 3$ blockade increased intratumoral $\mathrm{CD}^{+}{ }^{+} \mathrm{T}$ cell and NK cell cytotoxicity and diminished Treg and MDSC counts in a murine melanoma model. ${ }^{123} 124$ The norepinephrine- $\beta$-adrenergic signaling axes can suppress the ability of $\mathrm{T}$ cells and macrophages to produce TNF- $\alpha$, and more generally, psychological stress has been shown to correlate with MDSC levels in stage II and III breast cancer patients. ${ }^{125} 126$

In addition to immune suppression, $\beta$-adrenergic signaling contributes to tumorigenesis by enhancing cancer proliferation, angiogenesis, metastasis, and drug resistance, and stress has long been considered to negatively impact prognoses. ${ }^{127} 128$ As seen with adenosine, kynurenine, and PGE2, these 'fight-or-flight' metabolites function through immunosuppressive paracrine signaling and tumorigenic autocrine signaling by agonizing multiple receptors on immune or tumorous cells.

\section{INTERACTIONS BETWEEN IMMUNOSUPPRESSIVE METABOLITE AXES}

As we have described, the metabolic and signaling networks of adenosine, kynurenine, PGE2, and nor(epinephrine) are often redundant, that is (1) there can exist multiple biosynthetic routes for each metabolite, or multiple enzymes can catalyze the same reaction within a specific metabolic pathway (figure 1), and (2) each metabolite might agonize multiple unique receptors to induce suppressive signaling cascades (figure 2). To wit, $A_{2 A} A R$ and $A_{2 B} A R$ for adenosine, AhR and GPR35 for kynurenines, EP2 and EP4 for PGE2, and $\beta 1, \beta 2$, and $\beta 3$ for (nor) epinephrine. In addition, agonism of different receptors by different metabolites might induce the same immunosuppressive signaling network, as seen with induction of cAMP-PKA-CREB signaling by $\mathrm{A}_{2 \mathrm{~A} / \mathrm{B}} \mathrm{AR}, \mathrm{EP} 2 / 4$, and $\beta$-adrenergic receptor agonism, as well as several other instances of crosstalk (figure 3). In this manner, the loss of immunosuppressive signaling mediated by one metabolite can be compensated for by another, and multiple metabolites might act in combination to amplify their impact. For instance, some Tregs can synthesize both adenosine and PGE2, and adenosine and PGE2 have been shown to cooperatively amplify immunosuppressive cAMP-PKA signaling to inhibit cytotoxic cells. ${ }^{129} 130$

In a similar vein, the kynurenine and PGE2 pathways can amplify each other through a 'cross-metabolite' feedforward loop (figure 3). COX-2/PGE2 enhances TDO expression in glioma and drives IDO expression 
in numerous cancers, while $\mathrm{AhR}$ associates with the COX-2 gene's promoter to drive its transcription. ${ }^{131-133}$ The PGE2 synthesis enzyme, cPGES (p23), also complexes with AhR in the cytoplasm to protect it from degradation. ${ }^{134}$ As adenosine and PGE2 can stimulate feed forward synthesis loops by themselves in certain cells and cooperatively amplify cAMPsignaling, it is intuitive that they could stimulate each other's synthesis through another 'cross-metabolite' feedforward loop. ${ }^{129-131}{ }^{135}$ Specifically, $\mathrm{A}_{2 \mathrm{~A}}$ AR agonism and cAMP signaling upregulates COX-2 expression and PGE2 production, and PGE2 or adenosine can induce TAMs to express CD73 (figure 3). ${ }^{136} 137$ Norepinephrine and epinephrine also interact with the other cAMP-signaling immunosuppressive metabolites, though explicit cross-metabolite feed forward loops have yet to be demonstrated. It has been shown that norepinephrine agonism of the $\beta 2$-adrenergic receptor promotes expression of COX-2 and cPGES, resulting in elevated tumorous PGE2. ${ }^{138}$ Macrophages incubated with epinephrine also upregulated expression of COX-2, IDO1, and IL-10. ${ }^{139}$

Therefore, these metabolites are not only functioning in parallel within the tumor but may often be interacting to activate and enhance their immunosuppressive potential (figure 3). As such, attempting to alleviate immune suppression in the tumor microenvironment by targeting one component of a synthesis or signaling pathway, or even one entire pathway, may prove insufficient without patient stratification and proper therapeutic choices for the relevant checkpoints at hand.

\section{CLINICAL IMPLICATIONS OF IMMUNOSUPPRESSIVE METABOLITES}

Clinical data demonstrate that elevated immunosuppressive metabolite levels and increased expression of many of their synthesis enzymes correlate with worse prognosis. As such, the pharmacological blockade of these metabolites is of great interest and has driven the discovery of multiple small molecules that antagonize their cognate receptors or inhibitors that target their synthesis enzymes. Therefore, for each metabolite, we will highlight clinical correlations before briefly describing completed and ongoing clinical efforts that target its synthesis and signaling pathways.

For the adenosine axis, expression of CD39 and CD73 predict poor prognosis in numerous cancers, as does $\mathrm{A}_{2 \mathrm{~A}} \mathrm{AR}$ expression. ${ }^{140-142}$ Tumorous adenosine concentrations have rarely been directly determined, although a quantification method has been recently described. ${ }^{143}$ In addition, an analysis of TCGA transcriptomic data from nearly 10,000 tumors showed that across all cancer types, an 'adenosine signaling gene expression signature' negatively correlates with survival and predicts reduced response to PD- 1 and CTLA- 4 blockade. ${ }^{12}$ Preclinical results have also showed an association between CD38 and anti-PD-1/PD-L1 resistance, and in patients with ovarian cancer, the frequency of $\mathrm{PD}-1^{+} / \mathrm{CD} 38^{+}$tumor-infiltrating lymphocytes (TILs) is negatively associated with disease stage, lymph node metastasis, and postoperative chemotherapy prognosis. ${ }^{144} 145$

Several ongoing or completed trials have focused on various targets within the adenosine axis, and selected trials for the adenosine, kynurenine, PGE2, and nor(epinephrine) pathways are briefly highlighted in table 1. For instance, a phase I/II trial targeting CD38 (Isatuximab) and PD-1 (Cemiplimab) reported a manageable safety profile, reduction of $\mathrm{CD} 8^{+}$immune subsets in the tumor microenvironment, and enhanced activation of peripheral $\mathrm{T}$ cells, and that $20.8 \%$ and $65 \%$ of metastatic castration-resistant prostate cancer and non-small cell lung cancer (NSCLC) patients, respectively, achieved stable disease. ${ }^{146}$ Phase I trials of CD73-targeting antibodies (Oleclumab) or $\mathrm{A}_{2 \mathrm{~A}} \mathrm{AR}$ antagonists (Ciforadenant, AZD4635) alone, or in combination with approved $\alpha \mathrm{PD}-\mathrm{L} 1$ checkpoint inhibitor antibodies (durvalumab, atezolizumab), showed manageable safety profiles, ${ }^{147-150}$ and combination therapy of CPI-006 ( $\alpha \mathrm{CD}-73$ antibody) and Ciforadenant was also well-tolerated. ${ }^{151}$ Larger trials testing efficacy of $\mathrm{A}_{2 \mathrm{~A}} \mathrm{AR}$ inhibition and $\mathrm{CD} 73$ blockade are ongoing, and a dual $\mathrm{A}_{2 \mathrm{~A}} \mathrm{AR} / \mathrm{A}_{2 \mathrm{~B}} \mathrm{AR}$ antagonist, etrumadenant, showed promising safety and $\mathrm{PK} / \mathrm{PD}$ in a phase I clinical trial and is being evaluated further. ${ }^{152} 153$

Kynurenine levels in clinical samples are measured more routinely than adenosine, and an elevated ratio of kynurenine to tryptophan in the serum correlates with worse prognosis across cancers, as does elevated IDO1, IDO2, and/or TDO expression. ${ }^{36}{ }^{154-158}$ Kynurenine levels are expected to increase predominantly in the tumor microenvironment, but in some cases, there is an observable systemic increase. ${ }^{157159}$ For instance, in diffuse large B-cell lymphoma patients, kynurenine serum levels were up to 10 -fold higher than typical. ${ }^{157}$ When treated with rituximab-cyclophosphamide-hydroxydaunorubicinvincristine-prednisone regimen (R-CHOP) therapy, patients with high serum kynurenine levels $(>1.5 \mu \mathrm{M})$ experienced significantly reduced overall survival $(58 \%)$ compared with the patients with normal levels $(<1.5 \mu \mathrm{M})$ $(85 \%){ }^{157}$ Elevated kynurenine:tryptophan ratios also correlate with reduced response to Nivolumab ( $\alpha$ PD-1 antibody) in patients with renal cell carcinoma, as though kynurenine were acting as an adaptive mechanism of resistant to checkpoint inhibition. ${ }^{160}$ Conversely, the IDO/AhR signaling axis has been proposed as 'upstream' of PD-1 expression, as heightened serum and tumor kynurenine levels correlate with increased AhR nuclear localization and PD-1 expression on tumor-infiltrating $\mathrm{CD}^{+} \mathrm{T}$ cells in breast and colon cancer (figure 3 ). Therefore, it remains unclear if kynurenine/AhR drives PD-1 expression or drives resistance to PD-1 blockade, raising doubt about the ability of PD-1 blockade and IDO1 inhibition to synergize. ${ }^{35161}$

Notably, the IDO1 inhibitor, epacadostat, provided no additional benefit to pembrolizumab treatment ( $\alpha$ PD-L1 antibody) in a recent failed phase III clinical trial, 


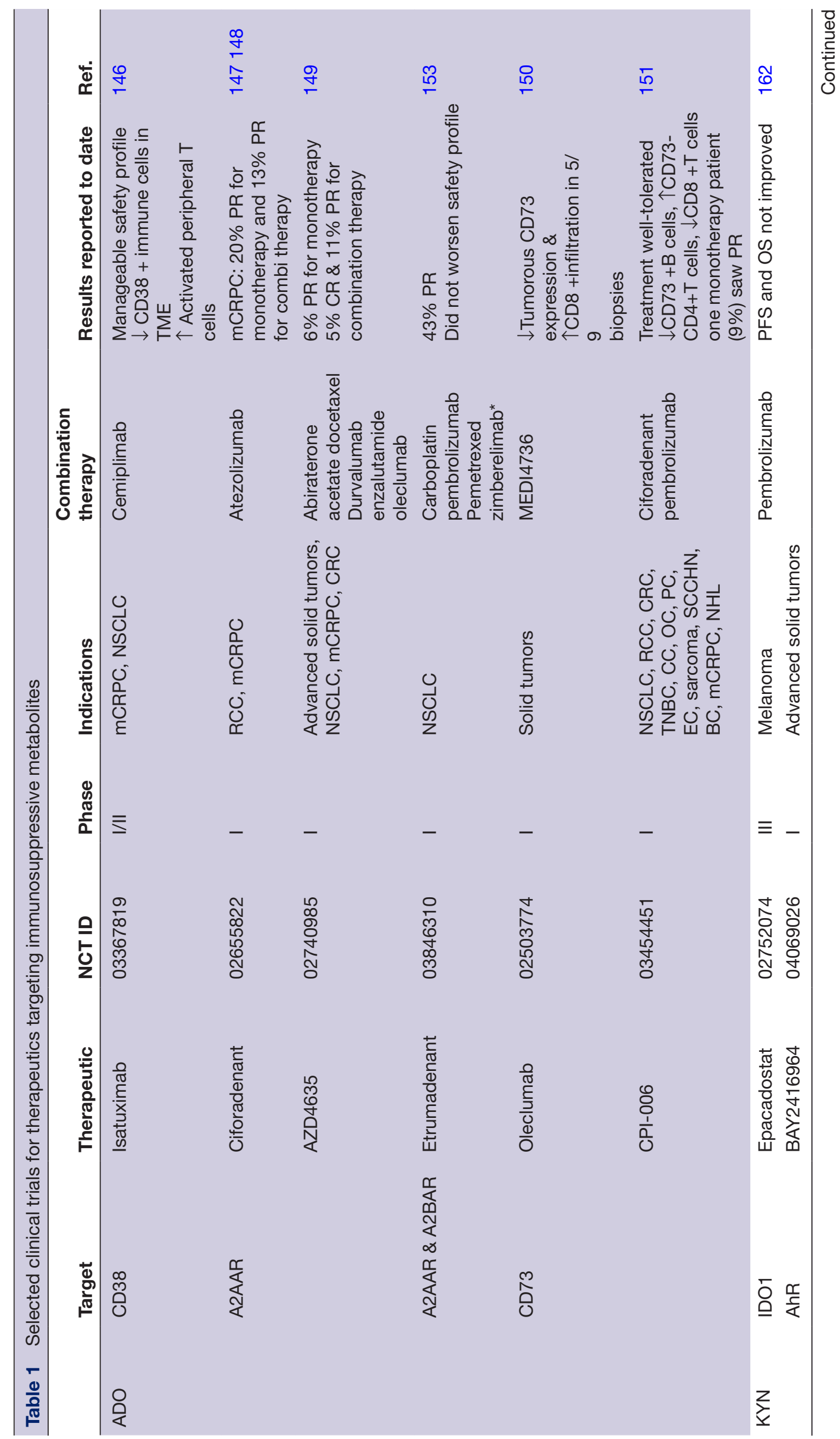




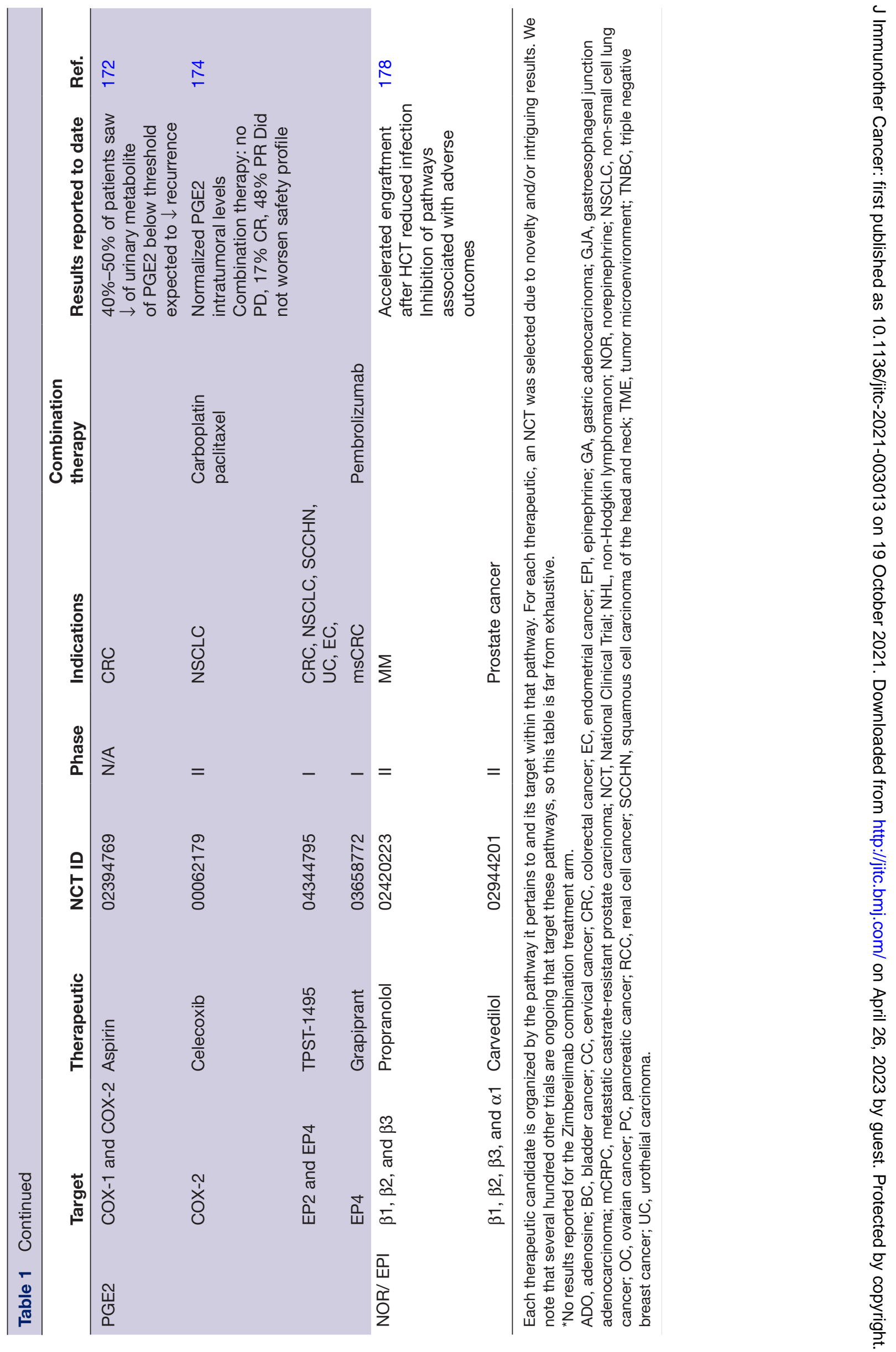


rendering the overall status of IDO1 blockade as a therapeutic strategy uncertain. ${ }^{162}$ Postmortem analyses have thoroughly detailed possible contributing factors toward Epacadostat's failure, including but not limited to: (1) lack of patient pre-screening for tumorous IDO1/IDO2/ TDO expression, as IDO2/TDO activities might compensate for blockade of IDO1; (2) inappropriate dosing regimens and lack of confirmation that kynurenine-AhR signaling was sufficiently reduced; (3) the possibility that Epacadostat may activate AhR due to structural similarity to AhR agonists; (4) uncertainty if PD-1 and IDO1 inhibition act synergistically; and (5) restriction of enrollees to melanoma patients, as melanoma may be a nonresponsive tumor type. ${ }^{161163}$ Recent work has also shown that a large portion of tumors may express TDO. ${ }^{37}$ Interestingly, Epacadostat's failure may have inadvertently cast light on the importance of broadly targeting an immunosuppressive metabolite's signaling or synthesis pathway. Despite its well-publicized disappointment, Epacadostat is still being tested in 18 ongoing trials. In addition, four other IDO1 inhibitors (Indoximod, BMS-986205, KHK2455, and MK-7162), a dual IDO1/TDO inhibitor (DN1406131), and two AhR inhibitors (KYN-175 and BAY2416964) are being evaluated in the clinic for various malignancies.

As with the kynurenine and adenosine synthesis pathways, the expression levels of several enzymes that catalyze production of PGE2 (such as phospholipases, COX-2, and PGES, and MRP transporters) correlate with poor clinical prognoses. ${ }^{52} 164165$ While rarely measured directly, PGE2 levels are higher in gliomas and pituitary adenomas than in normal tissues, and higher in the serum of NSCLC patients than controls. ${ }^{49} 166-168$ Notably, non-steroidal anti-inflammatory drugs (NSAIDs) inhibit the COX enzymes. Retrospective analyses have shown that long term use of Aspirin, which inhibits both COX-1 and COX-2, and other COX-2-specific NSAIDs (eg, Celecoxib) reduce risk of developing numerous cancer types, and Aspirin reduces mortality risk after diagnosis. ${ }^{169-172}$ In addition, PGE2 signaling increases $\mathrm{CD} 8^{+} \mathrm{T}$ cell PD-1 expression in lung cancer (figure 3), and recent preclinical studies have demonstrated that Aspirin synergizes with PD-1 blockade to enhance tumorous control and rejection. ${ }^{114} 173$ In the clinic, Aspirin has shown promise as a cancer preventative modality by limiting PGE2 production. ${ }^{172}$ Currently, Celecoxib is being evaluated in 35 ongoing clinical trials (defined as trials listed as 'Not yet recruiting', 'Recruiting', 'Enrolling by invitation', and 'Active, not recruiting' in the NCT.gov database) across many cancer indications, some of which incorporate PD-1/PD-L1 blockade and/or chemotherapy as a combination therapy. ${ }^{174}$ Other small molecule inhibitors of COX enzymes (etodolac, diclofenac, meloxicam) are also being assessed for cancer indications. Less effort has been aimed at addressing EP2-mediated and EP4mediated signaling: a single EP4 antagonist, Grapiprant, is being tested in combination with pembrolizumab in a phase I trial, and a dual EP2/EP4 antagonist, TPST-1495, is being tested in a phase I trial, also in combination with pembrolizumab.

Upregulated expression of norepinephrine or epinephrine-producing enzymes or their elevated levels also correlate with more advanced and/or aggressive disease ${ }^{6162}$ Analogous to NSAIDs, the use of $\beta$-adrenergic antagonists, commonly called $\beta$-blockers, has been retrospectively associated with a reduction in cancer diagnosis and mortality risk after diagnosis. ${ }^{175} 176$ 'Selective' betablockers antagonize the $\beta 1$ receptor (eg, Metoprolol and Atenolol) while 'non-selective' beta-blockers antagonize multiple adrenergic receptors, for instance, propranolol ( $\beta 1, \beta 2$, and $\beta 3$ receptors) and carvedilol ( $\beta 1, \beta 2$, $\beta 3$, and $\alpha 1$ receptors). These retrospective analyses have routinely showed enhanced benefit from 'non-selective' beta-blockers, suggesting that broad prevention of (nor) epinephrine-signaling is important for therapeutic benefit. ${ }^{177} 178$ The 'non-selective' antagonists propranolol (24 ongoing trials) and carvedilol (2 ongoing trials) are being broadly investigated as cancer therapies, while 'selective' agonists Metoprolol and Atenolol are being evaluated primarily for analgesia in cancer indications.

Increased expression of enzymes that catalyze the synthesis of the immunosuppressive metabolites adenosine, kynurenine, PGE2, and epinephrine correlates with worsened patient prognosis, immune suppression, and even poor response to checkpoint inhibitor antibody therapies. As such, numerous clinical trials and therapeutic efforts have been initiated to prevent their impact. However, the redundancies seen in and between immunosuppressive metabolic synthesis and signaling pathways makes preventing their activity a challenge.

\section{CHALLENGES AND PATHWAYS FORWARD}

The recent clinical failure of Epacadostat, an IDO1specific inhibitor, put the status of kynurenine-targeting therapeutics in jeopardy. However, thorough postmortem analyses have granted insights toward how such a failure can be avoided in the future, potentially through patient stratification, dosing optimization, or by broadening therapeutic scope to account for IDO/TDO redundancies, or more generally, synthesis or signaling redundancies found in immunosuppressive metabolite pathways. Here, we will describe avenues to alleviate the impact of suppressive metabolites by accounting for each metabolites intranetwork- and internetwork redundancies. Avenues include patient stratification, combination therapies, development of broad-spectrum (pan) inhibitors or antagonists, and/or development of new therapeutics that target the 'weakest link' of a metabolite's pathways (eg, a receptor for which no redundancy exists). Pan-inhibitors/antagonists and therapeutics against targets that lack redundancies may prove particularly promising.

For kynurenine-mediated immune suppression, patient stratification to ensure $\mathrm{IDO}^{+} \& \mathrm{TDO}^{-}$expression has been proposed as a necessary measure to improve efficacy of IDO1-targeting monotherapies. However, such 
baseline stratification prior to therapy may fail to account for the fact that the presence of activated $\mathrm{T}$ cells, such as could occur with PD-1 or CTLA-4 blockade, can itself induce IDO1 expression, while PGE2 has been shown to induce both IDO1 and TDO (figure 3). ${ }^{132} 133179$ Induction of reactive IDO or TDO during therapy would not be detected by baseline screening but would still be immunosuppressive and a target for therapy. Hence, initial biomarker stratification might be helpful but may not be definitive and should be followed by metabolomics analyses to confirm in vivo reduction in kynurenine levels following intervention. Kynurenine metabolomic analyses are relatively routine, and they can be coupled with analysis of IDO1, IDO2, and TDO expression levels that might deduce the mechanism of resistance to IDO1 inhibition (eg, increased IDO1 expression, induced TDO expression) to adjust accordingly. ${ }^{161}$ Preclinical studies have shown that kynurenine synthesis can be targeted by combining TDO and IDO1 inhibitors, or by using dual IDO1/TDO and pan-IDO1/IDO2/TDO inhibitors. Such therapies have claimed durable benefits in murine tumor models, but pan-inhibition of the kynurenine pathway can (1) drastically raise levels of serotonin and other tryptophan metabolites that cause toxicities and neurological impacts and (2) prevent intracellular $\mathrm{NAD}^{+}$synthesis if the $\mathrm{NAD}^{+}$salvage pathway is inefficient or not functional. Therefore, the tolerability profile of pan-inhibitors must be fully investigated and should consider all of tryptophan and kynurenine metabolism. ${ }^{180} 181$

$\mathrm{AhR}$ is the sole receptor for which kynurenine is known to be a ligand (figure 2). Thus, antagonizing AhR or depleting kynurenine directly would not be expected to be limited by IDO1/IDO2/TDO redundancies. In this vein, targeting kynurenine-mediated immune suppression with AhR antagonists has shown promise in preclinical models, and tumorous degradation of kynurenine using an engineered kynureninase enzyme (PEG-KYNase) has also shown efficacy. ${ }^{182-184}$ Still, expectations should be tempered for both therapeutic routes, as neither would prevent tryptophan depletion and any resulting immune suppression. In addition, AhR controls broad transcriptional programs impacting gut homeostasis, immunity, and numerous other processes, so antagonism could have unpredictable impacts. ${ }^{185} 186$ The PEG-KYNase utilized for preclinical studies is of bacterial origin, sparking immunogenicity and tolerability concerns, and its catalytic product, anthranilic acid, might re-enter the canonical kynurenine pathway if it were hydroxylated (figure 1). ${ }^{187}$

Similar challenges and opportunities exist for targeting adenosine immunosuppression. In murine models, combination therapies against CD73 and CD39 or CD73 and $\mathrm{A}_{2 \mathrm{~A}} \mathrm{AR}$ improve response compared with $\mathrm{CD} 73$, CD39, or $A_{2 A} A R$ monotherapy. This improved response implies that single-target therapeutics do not fully prevent adenosine synthesis or signaling, as may be expected from the adenosine axis' redundancies. Complete inhibition of adenosine synthesis is very challenging due to the diversity of enzymes and metabolic pathways that contribute toward its production, but dual $\mathrm{A}_{2 \mathrm{~A}} \mathrm{AR} / \mathrm{A}_{2 \mathrm{~B}} \mathrm{AR}$ inhibitors might largely prevent adenosine signaling. To this end, ongoing clinical trials testing the antitumor activity and safety of Etrumadenant will begin reveal the potential of $\mathrm{A}_{2 \mathrm{~A} / \mathrm{B}} \mathrm{AR}$ dual antagonism. ${ }^{188}$ However, it is important to note that adenosine signaling through $\mathrm{A}_{2 \mathrm{~A}} \mathrm{AR}$ and $\mathrm{A}_{2 \mathrm{~B}} \mathrm{AR}$ is important for normal physiological functions such as maintenance of the sleep cycle and cardiovascular regulation, so non-tissue-specific blockade of adenosine signaling could have safety concerns. ${ }^{189} 190$ Alternatively, it may be possible to degrade the adenosine molecule itself using an enzymatic therapy, similar to the PEG-KYNase mechanism of action. Adagen, a PEG-conjugated enzyme from Bos taurus, can deaminate adenosine into inosine, and its repurposing for cancer has been proposed recently. ${ }^{86}$ Because of its non-human origin, Adagen could suffer from the same tolerability and immunogenicity issues noted for PEG-KYNase, and efficacy-limiting anti-drug antibodies arise even when Adagen is used to treat immunocompromised Adenosine Deaminase Severe Combined Immunodeficiency (ADA-SCID) patients. ${ }^{191}$ Recently, a PEGylated, engineered ADA 2 showed antitumor efficacy in preclinical studies. ${ }^{192}$ Therefore, therapeutic efforts to target adenosine directly or to block both $A_{2 A} A R$ and $A_{2 B} A R$ signaling might be well positioned to counter the internal pathway redundancies seen in the adenosine axis.

Even if adenosine-mediated immunosuppression were eliminated, cancers have alternative routes to promote cAMP-mediated immunosuppressive signaling. However, established therapeutics that target PGE2 or the epinephrine axes exist and might be repurposed. As we've noted, the non-selective $\beta 1 / \beta 2 / \beta 3$ adrenergic receptor antagonist, propranolol, and the dual COX-1/2 inhibitor, aspirin, correlate with reduced cancer risk in retrospective analyses. ${ }^{193} 194$ By targeting multiple receptors/enzymes, these therapies may be less likely to be impacted by PGE2/ (nor) epinephrine pathway redundancies. A dual EP2/EP4 antagonist is also being tested clinically, giving another broad-acting route toward preventing PGE2-signaling. Alternatively, inhibition of the adenylate cyclases which produce cAMP from ATP might be advantageous due to the position of cAMP as a focal point connecting various immunosuppressive signaling pathways. Considering that immune cells largely express adenylate cyclase isoform 7 , delivery of a specific inhibitor to tumorous immune cells may thwart the immunosuppressive signaling contributions of the adenosine, PGE2, and (nor)epinephrine pathways simultaneously. ${ }^{195}$

cAMP-mediated signaling also impacts numerous other aspects of disease progression, specifically promoting tumor growth and metastasis. ${ }^{196}$ Thus, while retrospective studies provide valuable insights, each treatment or combination therapy must be evaluated for efficacy as immunotherapies in preclinical models and then in human studies. It will be important deconvolute the impacts of altering tumorous signaling versus improving antitumor immunity, and therapeutic benefit might be 
improved for either impact by employing broad-spectrum blockade.

Promisingly, perioperative non-selective $\beta$-adrenergic antagonism (Propranolol) and COX-2 selective inhibition (via Etodolac) was well tolerated and improved immune function in a recent small clinical trial of colon cancer. ${ }^{197}$ It will be particularly important to determine safety profiles associated these therapies. For instance, COX inhibition results in gastrointestinal and cardiovascular hazards due to reduced production of important prostaglandins (other than PGE2), and $\beta$-adrenergic signaling contributes to the regulation of many bodily functions apart from immune response. ${ }^{10} 53$ Importantly, between 1999 and 2004, the COX-2 selective inhibitors Rofecoxib and Celecoxib caused more than 26000 deaths compared with less than 10000 deaths in patients taking 'traditional' non-selective NSAIDs (eg, aspirin). ${ }^{198}$ Hence, treatment with traditional NSAIDs may be preferrable to COX-2 selective inhibitors in terms of both patient safety and accounting for pathway redundancy. Pan-cAMP inhibition may also have other unintended consequences. For example, while exercise stimulated antitumor immunity and tumor regression in tumor-bearing mice, the benefits of exercise were negated on eliminating epinephrinemediated signaling. ${ }^{199}$

Patient stratification for adenosine, PGE2, or nor(epinephrine) targeting therapies could be beneficial, however, will likely prove challenging because many enzymes catalyze their production, their signaling pathways intersect, and measuring PGE2 and adenosine levels is uncommon. A promising alternative to direct adenosine measurement is the recently described 'adenosine signaling gene expression signature' which correlated well with in vivo tumorous adenosine levels in mice and may have utility as a proxy for adenosine levels in the clinic. ${ }^{12}$ While developing robust methods to directly measure PGE2 would be ideal, it may be also be possible to develop a similar 'PGE2 signaling gene expression signature', or a pan-cAMP-signaling signature that encompasses adenosine, PGE2, and nor(epinephrine). Interestingly, seven of the 14 genes that comprise the adenosine signaling signature are upregulated by PGE2mediated signaling (FOXP3, COL3A1, APP, FOS), part of the PGE2 signaling pathway (CREB and MAPK1), or utilized for PGE2 synthesis (PTGS2, that is, COX-2).$^{200-205}$ Therefore, this signature likely encompasses aspects of PGE2-signaling or general cAMP-mediated immunosuppression, and with fine-tuning, may be able to gage individual contributions. Certain patient stratification attempts may also prove more straightforward. Targeting PGE2 in brain malignancies might preferentially employ acetaminophen due to its ability to: (1) traverse the bloodbrain barrier (unlike many other COX inhibitors), and (2) inhibit COX-3, the primary COX isoform expressed in brain tissue. ${ }^{206207}$

Other therapeutic routes to prevent the impact of immunosuppressive metabolites are also being developed. CAR-T cell therapies might be engineered to resist immunosuppressive metabolic signaling. For instance, $A_{2 A} A R$ signaling can limit the efficacy CAR-T cells, but silencing of $\mathrm{A}_{2 A} \mathrm{AR}$ expression afforded resistance in a murine model. ${ }^{208}$ CAR-T cells have also been engineered to express a peptide, RIAD, which inhibits cAMP-mediated signaling cascades by interacting with PKA, potentially blunting PGE2, (nor)epinephrine and adenosine signaling. ${ }^{209} 210$ These 'metabolically armored' CAR-T cells demonstrated improved control of tumor growth and immune cell activity in murine models. ${ }^{209}$ Finally, ongoing clinical evaluations have been keen to demonstrate synergistic benefits from targeting synthesis enzyme or metabolite-receptors in combination with established checkpoint inhibitors but have almost universally been performed with PD-1/PD-L1 blockade. However, blockade of other protein-ligand interactions might also provide synergistic benefit. For instance, pharmacological blockade of CD73 enhanced the immunostimulatory efficacy of both PD-1 and CTLA-4 antibodies in mouse models, and $\beta$-adrenergic signaling has been shown to limit therapeutic efficacy of $\alpha$ PD- 1 and $\alpha 4-1 B B$ antibodies (figure 3). ${ }^{117} 211$

\section{CONCLUSION}

Herein, we have detailed the pathway and signaling redundancies prevalent for immunosuppressive metabolites, as well as highlighting overlap between signaling pathways, each pathway's clinical relevance, and ongoing therapeutic efforts. Redundancy is not a novel concept in tumorous immune evasion; for instance, $\mathrm{CD}^{+}$TILs from mice treated with anti-PD-1 upregulate expression of CTLA-4. ${ }^{212}$ However, the level of redundancy inherent in the ability of each of these individual metabolites to suppress immunity is surprising. Because compensating metabolic pathways may limit efficacy of inhibitors of single enzymes (eg, IDO1), and several metabolites agonize multiple receptors (eg, EP2/EP4), we've emphasized the importance of therapies that broadly target each pathway. To this end, clinical trials are currently testing 'pan-antagonists' of each of the 'metabolic immunosuppressive receptor' subclasses that is, $\mathrm{A}_{2 \mathrm{~A} / 2 \mathrm{~B}} \mathrm{AR}$, EP2/ EP4, $\beta$-adrenergic receptors, and AhR, as well as broadinhibitors of kynurenine (IDO1/TDO or IDO1/IDO2/ TDO) and PGE2 (COX-1 and COX-2) synthesis. In light of cross-metabolite pathway redundancies, most prominently cAMP-mediated signaling, it may also be important to consider combination therapies against multiple immunosuppressive metabolites. For instance, therapeutics that target the adenosine pathway might synergize with repurposed COX-1/COX-2 inhibiting NSAIDs and beta blockers, though more efforts are required to determine if these drugs truly function as 'metabolic immunotherapies'. Because of the similarity in each pathways synthesis and signaling redundancies, lessons earnt from targeting one immunosuppressive metabolic pathway might guide future successes (and help avoid potential pitfalls) for other metabolites. Finally, as safety concerns exist for 
each single-target inhibitor or antagonist, determining the safety profile of more broadly acting therapies (and their combinations) will be of the utmost importance.

Acknowledgements We thank the reviewers of this manuscript for their insightful commentary.

Contributors MRJ, DM, and JB wrote the review.

Funding MRJ is supported by a National Science Foundation Graduate Research Fellowship. DM receives funding from the NIH (R01CA103320 and R01CA211229). $\mathrm{JB}$ receives funding from the Emory University Winship Cancer Center and the Arnold and Mabel Beckman Foundation.

Disclaimer The content is solely the responsibility of the authors and does not necessarily reflect the official views of the National Science Foundation, the National Institutes of Health, the Winship Cancer Center, or the Beckman Foundation.

Competing interests JB has IP related to PEG-KYNase enzymes and has received consulting income from Ikena Oncology. DM has IP interests in the therapeutic use of IDO inhibitors; and has received consulting income and research support from NewLink Genetics/Lumos Pharma. MRJ is supported by a National Science Foundation Graduate Research Fellowship. DM receives funding from the NIH (R01CA103320 and R01CA211229). JB receives funding from the Emory University Winship Cancer Center and the Arnold and Mabel Beckman Foundation.

Patient consent for publication Not applicable.

Provenance and peer review Not commissioned; externally peer reviewed.

Open access This is an open access article distributed in accordance with the Creative Commons Attribution Non Commercial (CC BY-NC 4.0) license, which permits others to distribute, remix, adapt, build upon this work non-commercially, and license their derivative works on different terms, provided the original work is properly cited, appropriate credit is given, any changes made indicated, and the use is non-commercial. See http://creativecommons.org/licenses/by-nc/4.0/.

\section{ORCID iDs}

Maria Rain Jennings http://orcid.org/0000-0002-2898-5222

John Blazeck http://orcid.org/0000-0002-6110-2938

\section{REFERENCES}

1 Vinay DS, Ryan EP, Pawelec G, et al. Immune evasion in cancer: mechanistic basis and therapeutic strategies. Semin Cancer Biol 2015;35 Suppl:S185-98.

2 Vaddepally RK, Kharel P, Pandey R, et al. Review of indications of FDA-approved immune checkpoint inhibitors per NCCN guidelines with the level of evidence. Cancers 2020;12. doi:10.3390/ cancers12030738. [Epub ahead of print: 2003 2020].

3 Soda K. The mechanisms by which polyamines accelerate tumor spread. J Exp Clin Cancer Res 2011;30:95.

4 PeÑarando J, Aranda E, Rodríguez-Ariza A. Immunomodulatory roles of nitric oxide in cancer: tumor microenvironment says "NO" to antitumor immune response. Transl Res 2019;210:99-108.

5 Romero-Garcia S, Moreno-Altamirano MMB, Prado-Garcia H, et al. Lactate contribution to the tumor microenvironment: mechanisms, effects on immune cells and therapeutic relevance. Front Immunol 2016;7:52.

6 Proietti E, Rossini S, Grohmann U, et al. Polyamines and kynurenines at the intersection of immune modulation. Trends Immunol 2020;41:1037-50.

7 Sheth S, Brito R, Mukherjea D, et al. Adenosine receptors: expression, function and regulation. Int J Mol Sci 2014;15:2024-52.

8 Schwarcz R, Stone TW. The kynurenine pathway and the brain: challenges, controversies and promises. Neuropharmacology 2017;112:237-47.

9 Kalinski P. Regulation of immune responses by prostaglandin E2. $J$ Immunol 2012;188:21-8.

10 Tank AW, Lee Wong D. Peripheral and central effects of circulating catecholamines. Compr Physiol 2015;5:1-15.

11 Ballarín M, Fredholm BB, Ambrosio S, et al. Extracellular levels of adenosine and its metabolites in the striatum of awake rats: inhibition of uptake and metabolism. Acta Physiol Scand 1991;142:97-103.

12 Sidders B, Zhang P, Goodwin K, et al. Adenosine signaling is prognostic for cancer outcome and has predictive utility for immunotherapeutic response. Clin Cancer Res 2020;26:2176-87.
13 Allard D, Allard B, Stagg J. On the mechanism of anti-CD39 immune checkpoint therapy. J Immunother Cancer 2020;8.

14 Allard B, Longhi MS, Robson SC, et al. The ectonucleotidases CD39 and CD73: novel checkpoint inhibitor targets. Immunol Rev 2017;276:121-44.

15 Zimmermann H, Zebisch M, Sträter N. Cellular function and molecular structure of ecto-nucleotidases. Purinergic Signal 2012;8:437-502.

16 Rao SR, Snaith AE, Marino D, et al. Tumour-derived alkaline phosphatase regulates tumour growth, epithelial plasticity and disease-free survival in metastatic prostate cancer. Br J Cancer 2017;116:227-36.

17 Tsai LC, Hung MW, Chen YH, et al. Expression and regulation of alkaline phosphatases in human breast cancer MCF-7 cells. Eur $J$ Biochem 2000;267:1330-9.

18 Horenstein AL, Chillemi A, Zaccarello G, et al. A CD38/CD203a/ CD73 ectoenzymatic pathway independent of CD39 drives a novel adenosinergic loop in human T lymphocytes. Oncoimmunology 2013;2:e26246.

19 Horenstein AL, Quarona V, Toscani D, et al. Adenosine generated in the bone marrow niche through a CD38-mediated pathway correlates with progression of human myeloma. Mol Med 2016;22:694-704.

20 Bruzzone S, Guida L, Zocchi E, et al. Connexin 43 hemi channels mediate $\mathrm{Ca} 2+-$-regulated transmembrane NAD+ fluxes in intact cells. Faseb J 2001;15:10-12.

21 Dessauer CW. Adenylyl cyclase-A-kinase anchoring protein complexes: the next dimension in cAMP signaling. Mol Pharmacol 2009;76:935-41.

22 Godinho RO, Duarte T, Pacini ESA. New perspectives in signaling mediated by receptors coupled to stimulatory $G$ protein: the emerging significance of cAMP efflux and extracellular CAMPadenosine pathway. Front Pharmacol 2015;6:58.

23 Horenstein AL, Morandi F, Bracci C, et al. Functional insights into nucleotide-metabolizing ectoenzymes expressed by bone marrowresident cells in patients with multiple myeloma. Immunol Lett 2019;205:40-50.

24 Kaljas Y, Liu C, Skaldin M, et al. Human adenosine deaminases ADA1 and ADA2 bind to different subsets of immune cells. Cell Mol Life Sci 2017;74:555-70.

25 Bender DA. Biochemistry of tryptophan in health and disease. Mol Aspects Med 1983;6:101-97.

26 Prendergast GC, Smith C, Thomas S, et al. Indoleamine 2,3-dioxygenase pathways of pathogenic inflammation and immune escape in cancer. Cancer Immunol Immunother 2014;63:721-35.

27 Platten M, Wick W, Van den Eynde BJ. Tryptophan catabolism in cancer: beyond IDO and tryptophan depletion. Cancer Res 2012;72:5435 LP-40.

28 Ye Z, Yue L, Shi J, et al. Role of IDO and TDO in cancers and related diseases and the therapeutic implications. $J$ Cancer 2019;10:2771-82

29 Prendergast GC, Metz R, Muller AJ, et al. IDO2 in immunomodulation and autoimmune disease. Front Immunol 2014;5:585

30 Hornyák L, Dobos N, Koncz G, et al. The role of Indoleamine-2,3Dioxygenase in cancer development, diagnostics, and therapy. Front Immunol 2018;9:151.

31 González Esquivel D, Ramírez-Ortega D, Pineda B, et al. Kynurenine pathway metabolites and enzymes involved in redox reactions. Neuropharmacology 2017;112:331-45.

32 Takikawa O, Yoshida R, Kido R, et al. Tryptophan degradation in mice initiated by indoleamine 2,3-dioxygenase. J Biol Chem 1986;261:3648-53.

33 Kaper T, Looger LL, Takanaga $\mathrm{H}$, et al. Nanosensor detection of an immunoregulatory tryptophan influx/kynurenine efflux cycle. PLOS Biol 2007;5:e257.

34 Sinclair LV, Neyens D, Ramsay G, et al. Single cell analysis of kynurenine and system $L$ amino acid transport in T cells. Nat Commun 2018;9:1981.

35 Liu Y, Liang X, Dong W, et al. Tumor-repopulating cells induce PD-1 expression in $\mathrm{CD}^{+} \mathrm{T}$ cells by transferring kynurenine and AhR activation. Cancer Cell 2018;33:480-94.

36 Opitz CA, Litzenburger UM, Sahm F, et al. An endogenous tumourpromoting ligand of the human aryl hydrocarbon receptor. Nature 2011;478:197-203.

$37 \mathrm{Li} \mathrm{H}$, Ning S, Ghandi M, et al. The landscape of cancer cell line metabolism. Nat Med 2019;25:850-60.

38 Walczak K, Wnorowski A, Turski WA, et al. Kynurenic acid and cancer: facts and controversies. Cell Mol Life Sci 2020;77:1531-50. 
39 Gkotsos G, Virgiliou C, Lagoudaki I, et al. The role of sarcosine, uracil, and kynurenic acid metabolism in urine for diagnosis and progression monitoring of prostate cancer. Metabolites 2017;7:9.

40 Moffett JR, Arun P, Puthillathu N, et al. Quinolinate as a marker for kynurenine metabolite formation and the unresolved question of $\mathrm{NAD}^{+}$synthesis during inflammation and infection. Front Immunol 2020;11:31.

41 Lugo-Huitrón R, Ugalde Muñiz P, Pineda B, et al. Quinolinic acid: an endogenous neurotoxin with multiple targets. Oxid Med Cell Longev 2013:2013:2013.

42 Wu W, Bush KT, Nigam SK. Key role for the organic anion transporters, OAT1 and OAT3, in the in vivo handling of uremic toxins and solutes. Sci Rep 2017;7:4939.

43 Sarrouilhe D, Mesnil M. Serotonin and human cancer: a critical view. Biochimie 2019;161:46-50.

44 Kannen V, Bader M, Sakita JY, et al. The dual role of serotonin in colorectal cancer. Trends Endocrinol Metab 2020;31:611-25.

45 Herr N, Bode C, Duerschmied D. The effects of serotonin in immune cells. Front Cardiovasc Med 2017;4:48.

46 Smith WL. The eicosanoids and their biochemical mechanisms of action. Biochem J 1989;259:315-24.

47 Cordes T, Hoellen F, Dittmer C, et al. Correlation of prostaglandin metabolizing enzymes and serum PGE2 levels with vitamin D receptor and serum 25(OH)2D3 levels in breast and ovarian cancer. Anticancer Res 2012;32:351-7.

48 Loh J-K, Hwang S-L, Lieu A-S, et al. The alteration of prostaglandin E2 levels in patients with brain tumors before and after tumor removal. J Neurooncol 2002;57:147-50.

49 Hidalgo GE, Zhong L, Doherty DE, et al. Plasma PGE-2 levels and altered cytokine profiles in adherent peripheral blood mononuclear cells in non-small cell lung cancer (NSCLC). Mol Cancer 2002;1:5.

50 Fadok VA, Bratton DL, Konowal A, et al. Macrophages that have ingested apoptotic cells in vitro inhibit proinflammatory cytokine production through autocrine/paracrine mechanisms involving TGFbeta, PGE2, and PAF. J Clin Invest 1998;101:890-8.

51 Murakami M, Kudo I. Recent advances in molecular biology and physiology of the prostaglandin E2-biosynthetic pathway. Prog Lipid Res 2004;43:3-35.

52 Fletcher Jl, Haber M, Henderson MJ, et al. ABC transporters in cancer: more than just drug efflux pumps. Nat Rev Cancer 2010;10:147-56.

53 Grosser T, Yu Y, Fitzgerald GA. Emotion recollected in tranquility: lessons learned from the COX-2 SAGA. Annu Rev Med 2010;61:17-33.

54 Williams CS, Mann M, DuBois RN. The role of cyclooxygenases in inflammation, cancer, and development. Oncogene 1999;18:7908-16.

55 Gierse JK, McDonald JJ, Hauser SD, et al. A single amino acid difference between cyclooxygenase-1 (COX-1) and -2 (COX-2) reverses the selectivity of COX-2 specific inhibitors. J Biol Chem 1996;271:15810-4.

56 Mattila S, Tuominen $\mathrm{H}$, Koivukangas $\mathrm{J}$, et al. The terminal prostaglandin synthases mPGES-1, mPGES-2, and CPGES are all overexpressed in human gliomas. Neuropathology 2009;29:156-65.

57 Seo T, Tatsuguchi A, Shinji S, et al. Microsomal prostaglandin E synthase protein levels correlate with prognosis in colorectal cancer patients. Virchows Arch 2009;454:667-76.

58 Cox MB, Miller CA. Cooperation of heat shock protein 90 and p23 in aryl hydrocarbon receptor signaling. Cell Stress Chaperones 2004:9:4-20.

59 Gao L, Zackert WE, Hasford JJ, et al. Formation of prostaglandins E2 and D2 via the isoprostane pathway: a mechanism for the generation of bioactive prostaglandins independent of cyclooxygenase. J Biol Chem 2003;278:28479-89.

60 Eng JW-L, Kokolus KM, Reed CB, et al. A nervous tumor microenvironment: the impact of adrenergic stress on cancer cells, immunosuppression, and immunotherapeutic response. Cancer Immunol Immunother 2014;63:1115-28.

61 Verly IRN, Leen R, Meinsma JR, et al. Catecholamine excretion profiles identify clinical subgroups of neuroblastoma patients. Eur $J$ Cancer 2019;111:21-9.

62 Shi M, Liu D, Duan H, et al. The $\beta 2$-adrenergic receptor and HER2 comprise a positive feedback loop in human breast cancer cells. Breast Cancer Res Treat 2011;125:351-62.

63 Al-Wadei MH, Al-Wadei HAN, Schuller HM. Pancreatic cancer cells and normal pancreatic duct epithelial cells express an autocrine catecholamine loop that is activated by nicotinic acetylcholine receptors $\alpha 3, \alpha 5$, and $\alpha 7$. Mol Cancer Res 2012;10:239-49.

64 Wong HPS, Yu L, Lam EKY, et al. Nicotine promotes cell proliferation via alpha7-nicotinic acetylcholine receptor and catecholamine-synthesizing enzymes-mediated pathway in human colon adenocarcinoma HT-29 cells. Toxicol Appl Pharmacol 2007:221:261-7.

65 Brown SW, Meyers RT, Brennan KM, et al. Catecholamines in a macrophage cell line. J Neuroimmunol 2003;135:47-55.

66 Musso NR, Brenci S, Setti M, et al. Catecholamine content and in vitro catecholamine synthesis in peripheral human lymphocytes. $J$ Clin Endocrinol Metab 1996:81:3553-7.

67 Cosentino M, Fietta AM, Ferrari M, et al. Human CD4+CD25+ regulatory $\mathrm{T}$ cells selectively express tyrosine hydroxylase and contain endogenous catecholamines subserving an autocrine/ paracrine inhibitory functional loop. Blood 2007;109:632-42.

68 Cosentino M, Marino F, Bombelli R, et al. Endogenous catecholamine synthesis, metabolism, storage and uptake in human neutrophils. Life Sci 1999;64:975-81.

69 Molinoff PB, Axelrod J. Biochemistry of catecholamines. Annu Rev Biochem 1971;40:465-500.

70 Leone RD, Emens LA. Targeting adenosine for cancer immunotherapy. J Immunother Cancer 2018;6:1-9.

71 Vijayan D, Young A, Teng MWL, et al. Targeting immunosuppressive adenosine in cancer. Nat Rev Cancer 2017:17:709-24.

72 Mannino MH, Zhu Z, Xiao H, et al. The paradoxical role of IL-10 in immunity and cancer. Cancer Lett 2015;367:103-7.

73 Nakatsukasa H, Tsukimoto M, Harada $\mathrm{H}$, et al. Adenosine A2B receptor antagonist suppresses differentiation to regulatory $T$ cells without suppressing activation of T cells. Biochem Biophys Res Commun 2011;409:114-9.

74 Raskovalova T, Huang X, Sitkovsky M, et al. Gs protein-coupled adenosine receptor signaling and lytic function of activated NK cells. J Immunol 2005;175:4383-91.

75 van der Hoeven D, Wan TC, Gizewski ET, et al. A role for the lowaffinity $\mathrm{A} 2 \mathrm{~B}$ adenosine receptor in regulating superoxide generation by murine neutrophils. J Pharmacol Exp Ther 2011;338:1004-12.

76 Xaus J, Mirabet M, Lloberas J, et al. IFN-gamma up-regulates the A2B adenosine receptor expression in macrophages: a mechanism of macrophage deactivation. $J$ Immunol 1999;162:3607-14.

77 Németh ZH, Lutz CS, Csóka B, et al. Adenosine augments IL-10 production by macrophages through an $\mathrm{A} 2 \mathrm{~B}$ receptor-mediated posttranscriptional mechanism. J Immunol 2005;175:8260-70.

78 Su W, Chen X, Zhu W, et al. The cAMP-Adenosine feedback loop maintains the suppressive function of regulatory T cells. J Immunol 2019;203:1436-46.

79 Ohta A, Kini R, Ohta A, et al. The development and immunosuppressive functions of CD4(+) CD25(+) FoxP3(+) regulatory $T$ cells are under influence of the adenosine-A2A adenosine receptor pathway. Front Immunol 2012;3:190.

80 Maj T, Wang W, Crespo J, et al. Oxidative stress controls regulatory T cell apoptosis and suppressor activity and PD-L1-blockade resistance in tumor. Nat Immunol 2017:18:1332-41.

81 Novitskiy SV, Ryzhov S, Zaynagetdinov R, et al. Adenosine receptors in regulation of dendritic cell differentiation and function. Blood 2008;112:1822-31.

82 Raker VK, Becker C, Steinbrink K. The cAMP pathway as therapeutic target in autoimmune and inflammatory diseases. Front Immunol 2016;7:123.

83 Gödecke A. cAMP: fuel for extracellular adenosine formation? $\mathrm{Br} \mathrm{J}$ Pharmacol 2008;153:1087-9.

84 Welihinda AA, Kaur M, Raveendran KS, et al. Enhancement of inosine-mediated $A_{2 A} R$ signaling through positive allosteric modulation. Cell Signal 2018:42:227-35.

85 Junqueira SC, Dos Santos Coelho I, Lieberknecht V, et al. Inosine, an endogenous purine nucleoside, suppresses immune responses and protects mice from experimental autoimmune encephalomyelitis: a role for A2A adenosine receptor. Mol Neurobiol 2017:54:3271-85.

86 Wang T, Gnanaprakasam JNR, Chen X, et al. Inosine is an alternative carbon source for $\mathrm{CD} 8^{+}$-T-cell function under glucose restriction. Nat Metab 2020;2:635-47.

87 Mager LF, Burkhard R, Pett N, et al. Microbiome-derived inosine modulates response to checkpoint inhibitor immunotherapy. Science 2020;369:1481-9.

88 Munn DH, Mellor AL. Indoleamine 2,3-dioxygenase and tumorinduced tolerance. J Clin Invest 2007;117:1147-54.

89 Stone TW, Stoy N, Darlington LG. An expanding range of targets for kynurenine metabolites of tryptophan. Trends Pharmacol Sci 2013;34:136-43.

90 Seok S-H, Ma Z-X, Feltenberger JB, et al. Trace derivatives of kynurenine potently activate the aryl hydrocarbon receptor (AhR). $J$ Biol Chem 2018;293:1994-2005.

91 Lo R, Matthews J. High-Resolution genome-wide mapping of AHR and Arnt binding sites by ChIP-Seq. Toxicol Sci 2012;130:349-61. 
92 Ninomiya S, Narala N, Huye L, et al. Tumor indoleamine 2,3-dioxygenase (IDO) inhibits CD19-CAR T cells and is downregulated by lymphodepleting drugs. Blood 2015;125:3905-16.

93 Holmgaard RB, Zamarin D, Munn DH, et al. Indoleamine 2,3-dioxygenase is a critical resistance mechanism in antitumor T cell immunotherapy targeting CTLA-4. J Exp Med 2013;210:1389-402.

94 Spranger S, Koblish HK, Horton B, et al. Mechanism of tumor rejection with doublets of CTLA-4, PD-1/PD-L1, or IDO blockade involves restored IL-2 production and proliferation of CD8(+) T cells directly within the tumor microenvironment. $J$ Immunother Cancer 2014;2:3.

95 Mezrich JD, Fechner JH, Zhang X, et al. An interaction between kynurenine and the aryl hydrocarbon receptor can generate regulatory T cells. J Immunol 2010;185:3190-8.

96 Xue P, Fu J, Zhou Y. The aryl hydrocarbon receptor and tumor immunity. Front Immunol 2018;9:286.

$97 \mathrm{Li} \mathrm{Q}$, Harden JL, Anderson CD. Tolerogenic phenotype of IFN- $\gamma-$ induced IDO ${ }^{+}$dendritic cells is maintained via an autocrine IDOKynurenine/AhR-IDO loop. J Immunol 2016;197:962-70.

98 Yu J, Du W, Yan F, et al. Myeloid-Derived suppressor cells suppress antitumor immune responses through IDO expression and correlate with lymph node metastasis in patients with breast cancer. $J$ Immunol 2013;190:3783-97.

99 Quon T, Lin L-C, Ganguly A, et al. Therapeutic opportunities and challenges in targeting the orphan $\mathrm{G}$ protein-coupled receptor GPR35. ACS Pharmacol Trans/ Sci 2020;3:801-12.

100 Fallarini S, Magliulo L, Paoletti T, et al. Expression of functional GPR35 in human iNKT cells. Biochem Biophys Res Commun 2010;398:420-5.

101 Boldyrev AA, Bryushkova EA, Vladychenskaya EA. NMDA receptors in immune competent cells. Biochemistry 2012;77:128-34.

102 Mashkina AP, Tyulina OV, Solovyova TI, et al. The excitotoxic effect of NMDA on human lymphocyte immune function. Neurochem Int 2007:51:356-60.

103 Orihara K, Odemuyiwa SO, Stefura WP, et al. Neurotransmitter signalling via NMDA receptors leads to decreased T helper type 1like and enhanced $\mathrm{T}$ helper type 2-like immune balance in humans. Immunology 2018;153:368-79.

104 León-Ponte M, Ahern GP, O'Connell PJ. Serotonin provides an accessory signal to enhance T-cell activation by signaling through the 5-HT7 receptor. Blood 2007;109:3139-46.

105 Wang D, Dubois RN. Eicosanoids and cancer. Nat Rev Cancer 2010;10:181-93.

106 Regan JW. EP2 and EP4 prostanoid receptor signaling. Life Sci 2003;74:143-53.

107 Chemnitz JM, Driesen J, Classen S, et al. Prostaglandin E2 impairs CD4+ T cell activation by inhibition of Lck: implications in Hodgkin's lymphoma. Cancer Res 2006;66:1114-22.

108 Ahmadi M, Emery DC, Morgan DJ. Prevention of both direct and cross-priming of antitumor CD8+ T-cell responses following overproduction of prostaglandin E2 by tumor cells in vivo. Cancer Res 2008;68:7520-9.

109 Albu DI, Wang Z, Huang K-C, et al. EP4 Antagonism by E7046 diminishes Myeloid immunosuppression and synergizes with Tregreducing IL-2-Diphtheria toxin fusion protein in restoring anti-tumor immunity. Oncoimmunology 2017;6:e1338239.

110 Loynes CA, Lee JA, Robertson AL, et al. PGE production at sites of tissue injury promotes an anti-inflammatory neutrophil phenotype and determines the outcome of inflammation resolution in vivo. Sci Adv 2018;4:eaar8320.

111 Saleh LS, Vanderheyden C, Frederickson A, et al. Prostaglandin E2 and Its receptor EP2 modulate macrophage activation and fusion in Vitro. ACS Biomater Sci Eng 2020;6:2668-81.

112 Medeiros Al, Serezani CH, Lee SP, et al. Efferocytosis impairs pulmonary macrophage and lung antibacterial function via PGE2/ EP2 signaling. J Exp Med 2009;206:61-8.

113 Hinz B, Brune K, Pahl A. Prostaglandin E(2) upregulates cyclooxygenase-2 expression in lipopolysaccharide-stimulated RAW 264.7 macrophages. Biochem Biophys Res Commun 2000;272:744-8.

114 Wang J, Zhang L, Kang D, et al. Activation of PGE2/EP2 and PGE2/ EP4 signaling pathways positively regulate the level of PD-1 in infiltrating $\mathrm{CD}^{+} \mathrm{T}$ cells in patients with lung cancer. Oncol Lett 2018;15:552-8

115 Bylund DB, Eikenberg DC, Hieble JP, et al. International Union of Pharmacology nomenclature of adrenoceptors. Pharmacol Rev 1994;46:121-36.

116 Sharma D, Farrar JD. Adrenergic regulation of immune cell function and inflammation. Semin Immunopathol 2020;42:709-17.
117 Nissen MD, Sloan EK, Mattarollo SR. $\beta$-Adrenergic Signaling Impairs Antitumor CD8 ${ }^{+}$T-cell Responses to B-cell Lymphoma Immunotherapy. Cancer Immunol Res 2018;6:98-109.

118 Nijhuis LE, Olivier BJ, Dhawan S, et al. Adrenergic $\beta 2$ receptor activation stimulates anti-inflammatory properties of dendritic cells in vitro. PLoS One 2014;9:e85086.

119 Shakhar G, Ben-Eliyahu S. In vivo $\beta$-adrenergic stimulation suppresses natural killer activity and compromises resistance to tumor metastasis in rats. J Immunol 1998;160:3251 LP-8.

120 Mohammadpour H, MacDonald CR, Qiao G, et al. $\beta 2$ adrenergic receptor-mediated signaling regulates the immunosuppressive potential of myeloid-derived suppressor cells. J Clin Invest 2019;129:5537-52.

121 Iñigo-Marco I, Alonso MM. Destress and do not suppress: targeting adrenergic signaling in tumor immunosuppression. J Clin Invest 2019;129:5086-8.

122 Schmidt D, Peterlik D, Reber SO, et al. Induction of suppressor cells and increased tumor growth following chronic psychosocial stress in male mice. PLoS One 2016;11:e0159059.

123 Calvani M, Bruno G, Dal Monte $\mathrm{M}$, et al. $\beta_{3}$-Adrenoceptor as a potential immuno-suppressor agent in melanoma. Br J Pharmacol 2019;176:2509-24.

$124 \mathrm{Xu} \mathrm{W}, \mathrm{Wu}$ Y, Wang L, et al. Autoantibody against $\beta_{1}$-adrenoceptor promotes the differentiation of natural regulatory $T$ cells from activated $\mathrm{CD}^{+} \mathrm{T}$ cells by up-regulating AMPK-mediated fatty acid oxidation. Cell Death Dis 2019;10:158.

125 Kalinichenko VV, Mokyr MB, Graf LH, et al. Norepinephrinemediated inhibition of antitumor cytotoxic T Iymphocyte generation involves a beta-adrenergic receptor mechanism and decreased TNF-alpha gene expression. J Immunol 1999;163:2492-9.

126 Mundy-Bosse BL, Thornton LM, Yang H-C, et al. Psychological stress is associated with altered levels of myeloid-derived suppressor cells in breast cancer patients. Cell Immunol 2011;270:80-7.

127 Coelho M, Soares-Silva C, Brandão D, et al. $\beta$-Adrenergic modulation of cancer cell proliferation: available evidence and clinical perspectives. J Cancer Res Clin Oncol 2017;143:275-91.

128 Yang EV. Role for catecholamines in tumor progression: possible use for $\beta$-blockers in the treatment of cancer. Cancer Biol Ther 2010;10:30-2.

129 Su Y, Huang X, Raskovalova T, et al. Cooperation of adenosine and prostaglandin E2 (PGE2) in amplification of cAMP-PKA signaling and immunosuppression. Cancer Immunol Immunother 2008;57:1611-23

130 Whiteside TL, Jackson EK. Adenosine and prostaglandin e2 production by human inducible regulatory $\mathrm{T}$ cells in health and disease. Front Immunol 2013;4:212.

131 Degner SC, Papoutsis AJ, Selmin O, et al. Targeting of aryl hydrocarbon receptor-mediated activation of cyclooxygenase-2 expression by the indole-3-carbinol metabolite 3,3'-diindolylmethane in breast cancer cells. J Nutr 2009;139:26-32.

132 Ochs K, Ott M, Rauschenbach KJ, et al. Tryptophan-2,3dioxygenase is regulated by prostaglandin E2 in malignant glioma via a positive signaling loop involving prostaglandin E receptor-4. J Neurochem 2016;136:1142-54.

133 Hennequart M, Pilotte L, Cane S, et al. Constitutive IDO1 expression in human tumors is driven by cyclooxygenase-2 and mediates intrinsic immune resistance. Cancer Immunol Res 2017;5:695-709.

134 Pappas B, Yang Y, Wang Y, et al. P23 protects the human aryl hydrocarbon receptor from degradation via a heat shock protein 90-independent mechanism. Biochem Pharmacol 2018;152:34-44.

135 Song X, Zhang Y, Zhang L, et al. Hypoxia enhances indoleamine 2,3-dioxygenase production in dendritic cells. Oncotarget 2018;9:11572-80.

136 Fiebich BL, Biber K, Lieb K, et al. Cyclooxygenase-2 expression in rat microglia is induced by adenosine A2A-receptors. Glia 1996;18:152-80.

137 Al-Taei S, Salimu J, Spary LK, et al. Prostaglandin E mediated adenosinergic effects on $\mathrm{CD} 14^{+}$cells: self-amplifying immunosuppression in cancer. Oncoimmunology 2017;6:e1268308.

138 Nagaraja AS, Dorniak PL, Sadaoui NC, et al. Sustained adrenergic signaling leads to increased metastasis in ovarian cancer via increased PGE2 synthesis. Oncogene 2016:35:2390-7.

139 Muthuswamy R, Okada NJ, Jenkins FJ, et al. Epinephrine promotes Cox-2-dependent immune suppression in myeloid cells and cancer tissues. Brain Behav Immun 2017;62:78-86.

140 Wu Z, Yang L, Shi L, et al. Prognostic impact of adenosine receptor 2 (A2aR) and programmed cell death ligand 1 (PD-L1) expression in colorectal cancer. Biomed Res Int 2019;2019:1-10. 
141 Loi S, Pommey S, Haibe-Kains B, et al. CD73 promotes anthracycline resistance and poor prognosis in triple negative breast cancer. Proc Natl Acad Sci U S A 2013;110:11091-6.

142 Cai X-Y, Ni X-C, Yi Y, et al. Overexpression of CD39 in hepatocellular carcinoma is an independent indicator of poor outcome after radical resection. Medicine 2016;95:e4989.

143 Goodwin KJ, Gangl E, Sarkar U, et al. Development of a quantification method for adenosine in tumors by LC-MS/MS with dansyl chloride derivatization. Anal Biochem 2019;568:78-88.

144 Chen L, Diao L, Yang Y, et al. Cd38-Mediated immunosuppression as a mechanism of tumor cell escape from PD-1/PD-L1 blockade. Cancer Discov 2018;8:1156-75.

145 Zhou J, Wang W, Liang Z, et al. Clinical significance of CD38 and CD101 expression in PD $-1^{+} \mathrm{CD}^{+} \mathrm{T}$ cells in patients with epithelial ovarian cancer. Oncol Lett 2020;20:724-32.

146 Lin C-C, Zucali P, Carthon B, et al. Abstract LB040: targeting CD38 and PD-1 with isatuximab (Isa) plus cemiplimab (Cemi) in patients (PTS) with advanced malignancies: results from a phase 1/2 openlabel, multicenter study. Cancer Res 2021;81:LB040 LP-LB040.

147 Fong L, Hotson A, Powderly JD, et al. Adenosine 2A receptor blockade as an immunotherapy for treatment-refractory renal cell cancer. Cancer Discov 2020;10:40-53.

148 Harshman LC, Chu M, George S, et al. Adenosine receptor blockade with ciforadenant $+/$ - atezolizumab in advanced metastatic castration-resistant prostate cancer (mCRPC). J Clin Oncol 2020;38:129.

149 Lim EA, Bauer TM, Patel MR, et al. A phase I, open-label, multicenter study to assess the safety, pharmacokinetics, and preliminary antitumor activity of AZD4635 both as monotherapy and in combination in patients with advanced solid malignancies: results from prostate cancer patients (NCT02740985). J Clin Oncol 2020;38:5518.

150 Overman MJ, LoRusso P, Strickler JH, et al. Safety, efficacy and pharmacodynamics (PD) of MEDI9447 (oleclumab) alone or in combination with durvalumab in advanced colorectal cancer (CRC) or pancreatic cancer (panc). J Clin Oncol 2018;36:4123.

151 Luke JJ, Powderly JD, Merchan JR, et al. Immunobiology, preliminary safety, and efficacy of CPI-006, an anti-CD73 antibody with immune modulating activity, in a phase 1 trial in advanced cancers. J Clin Oncol 2019;37:2505.

152 Seitz L, Jin L, Leleti M, et al. Safety, tolerability, and pharmacology of $A B 928$, a novel dual adenosine receptor antagonist, in a randomized, phase 1 study in healthy volunteers. Invest New Drugs 2019;37:711-21.

153 Spira Al, Conkling PR, Johnson ML, et al. ARC-4 study: Efficacy and safety of AB928 plus carboplatin, pemetrexed and a PD-1 antibody in participants with metastatic non-small cell lung cancer (mNSCLC). J Clin Oncol 2020;38:e21659.

154 Pilotte L, Larrieu P, Stroobant V, et al. Reversal of tumoral immune resistance by inhibition of tryptophan 2,3-dioxygenase. Proc Natl Acad Sci U S A 2012;109:2497-502.

155 de Jong RA, Nijman HW, Boezen HM, et al. Serum tryptophan and kynurenine concentrations as parameters for indoleamine 2,3-dioxygenase activity in patients with endometrial, ovarian, and vulvar cancer. Int J Gynecol Cancer 2011;21:1320-7.

156 Giusti RM, Maloney EM, Hanchard B, et al. Differential patterns of serum biomarkers of immune activation in human T-cell lymphotropic virus type I-associated myelopathy/tropical spastic paraparesis, and adult T-cell leukemia/lymphoma. Cancer Epidemiol Biomarkers Prev 1996;5:699-704.

157 Yoshikawa T, Hara T, Tsurumi H, et al. Serum concentration of L-kynurenine predicts the clinical outcome of patients with diffuse large B-cell lymphoma treated with R-CHOP. Eur J Haematol 2010;84:304-9.

158 Löb S, Königsrainer A, Rammensee H-G, et al. Inhibitors of indoleamine-2,3-dioxygenase for cancer therapy: can we see the wood for the trees? Nat Rev Cancer 2009;9:445-52.

159 Suzuki Y, Suda T, Furuhashi K, et al. Increased serum kynurenine/ tryptophan ratio correlates with disease progression in lung cancer. Lung Cancer 2010;67:361-5.

160 Li H, Bullock K, Gurjao C, et al. Metabolomic adaptations and correlates of survival to immune checkpoint blockade. Nat Commun 2019:10:4346

161 Opitz CA, Somarribas Patterson LF, Mohapatra SR, et al. The therapeutic potential of targeting tryptophan catabolism in cancer. Br J Cancer 2020;122:30-44.

162 Long GV, Dummer R, Hamid O, et al. Epacadostat plus pembrolizumab versus placebo plus pembrolizumab in patients with unresectable or metastatic melanoma (ECHO-301/KEYNOTE-252): a phase 3, randomised, double-blind study. Lancet Oncol 2019:20:1083-97.
163 Van den Eynde BJ, van Baren N, Baurain J-F. Is there a clinical future for IDO1 inhibitors after the failure of Epacadostat in melanoma? Annu Rev Cancer Biol 2020;4:241-56.

164 Cai H, Chiorean EG, Chiorean MV, et al. Elevated phospholipase A2 activities in plasma samples from multiple cancers. PLoS One 2013;8:e57081.

165 Wu Y-C, Su L-J, Wang H-W, et al. Co-overexpression of cyclooxygenase-2 and microsomal prostaglandin E synthase-1 adversely affects the postoperative survival in non-small cell lung cancer. J Thorac Oncol 2010;5:1167-74.

166 Kökoğlu E, Tüter Y, Sandıkçı KS, et al. Prostaglandin E2 levels in human brain tumor tissues and arachidonic acid levels in the plasma membrane of human brain tumors. Cancer Lett 1998;132:17-21.

167 Akbari N, Ghorbani M, Salimi V, et al. Cyclooxygenase enzyme and PGE2 expression in patients with functional and non-functional pituitary adenomas. BMC Endocr Disord 2020;20:39.

168 Diakowska D, Markocka-Mączka K, Nienartowicz M, et al. Increased level of serum prostaglandin-2 in early stage of esophageal squamous cell carcinoma. Arch Med Sci 2014;10:956-61.

169 Harris R. Reduction in cancer risk by selective and nonselective cyclooxygenase-2 (COX-2) inhibitors. J Exp Pharmacol 2012;4:91-6.

170 Qiao Y, Yang T, Gan Y, et al. Associations between aspirin use and the risk of cancers: a meta-analysis of observational studies. BMC Cancer 2018;18:288

171 Mills EJ, Wu P, Alberton M, et al. Low-Dose aspirin and cancer mortality: a meta-analysis of randomized trials. $\mathrm{Am} \mathrm{J} \mathrm{Med}$ 2012:125:560-7.

172 Drew DA, Schuck MM, Magicheva-Gupta MV, et al. Effect of lowdose and standard-dose aspirin on PGE ${ }_{2}$ biosynthesis among individuals with colorectal adenomas: a randomized clinical trial. Cancer Prev Res 2020;13:877-88.

173 Zelenay S, van der Veen AG, Böttcher JP, et al. CyclooxygenaseDependent tumor growth through evasion of immunity. Cell 2015;162:1257-70.

174 Altorki NK, Keresztes RS, Port JL, et al. Celecoxib, a selective cyclo-oxygenase-2 inhibitor, enhances the response to preoperative paclitaxel and carboplatin in early-stage non-small-cell lung cancer. J. Clin. Oncol 2003;21:2645-50.

175 Chang P-Y, Huang W-Y, Lin C-L, et al. Propranolol reduces cancer risk: a population-based cohort study. Medicine 2015;94:e1097.

176 Choi CH, Song T, Kim TH, et al. Meta-Analysis of the effects of beta blocker on survival time in cancer patients. J Cancer Res Clin Oncol 2014; 140:1179-88

177 Watkins JL, Thaker PH, Nick AM, et al. Clinical impact of selective and nonselective beta-blockers on survival in patients with ovarian cancer. Cancer 2015;121:3444-51.

178 Knight JM, Rizzo JD, Hari P, et al. Propranolol inhibits molecular risk markers in hCT recipients: a phase 2 randomized controlled biomarker trial. Blood Adv 2020;4:467-76.

179 Spranger S, Spaapen RM, Zha Y, et al. Up-Regulation of PD-L1, IDO, and Tregs in the melanoma tumor microenvironment is driven by CD8+ T cells. Sci Trans/ Med 2013;5:200ra116-200.

180 Volpi-Abadie J, Kaye AM, Kaye AD. Serotonin syndrome. Ochsner J 2013;13:533-40.

181 Kanai M, Funakoshi $\mathrm{H}$, Takahashi $\mathrm{H}$, et al. Tryptophan 2,3-dioxygenase is a key modulator of physiological neurogenesis and anxiety-related behavior in mice. Mol Brain 2009;2:8.

182 Triplett TA, Garrison KC, Marshall N, et al. Reversal of indoleamine 2,3-dioxygenase-mediated cancer immune suppression by systemic kynurenine depletion with a therapeutic enzyme. Nat Biotechnol 2018;36:758-64.

183 Bianchi-Smiraglia A, Bagati A, Fink EE, et al. Inhibition of the aryl hydrocarbon receptor/polyamine biosynthesis axis suppresses multiple myeloma. J Clin Invest 2018;128:4682-96.

184 Campesato LF, Budhu S, Tchaicha J, et al. Blockade of the AhR restricts a Treg-macrophage suppressive axis induced by $L$ kynurenine. Nat Commun 2020:11:4011.

185 Rothhammer V, Quintana FJ. The aryl hydrocarbon receptor: an environmental sensor integrating immune responses in health and disease. Nat Rev Immunol 2019;19:184-97.

186 Larigot L, Juricek L, Dairou J, et al. Ahr signaling pathways and regulatory functions. Biochim Open 2018:7:1-9.

187 Baran H, Schwarcz R. Presence of 3-hydroxyanthranilic acid in rat tissues and evidence for its production from anthranilic acid in the brain. J Neurochem 1990;55:738-44.

188 Zhang J, Yan W, Duan W, et al. Tumor immunotherapy using $A_{2 A}$ adenosine receptor antagonists. Pharmaceuticals 2020;13. doi:10.3390/ph13090237. [Epub ahead of print: 0809 2020]. 
189 Huang Z-L, Zhang Z, Qu W-M. Roles of adenosine and its receptors in sleep-wake regulation. Int Rev Neurobiol 2014;119:349-71.

190 Gaudry M, Vairo D, Marlinge M, et al. Adenosine and its receptors: an expected tool for the diagnosis and treatment of coronary artery and ischemic heart diseases. Int J Mol Sci 2020;21:5321.

191 Hershfield MS. Peg-Ada replacement therapy for adenosine deaminase deficiency: an update after 8.5 years. Clin Immunol Immunopathol 1995;76:S228-32.

192 Wang L, Londono LM, Cowell J, et al. Targeting adenosine with adenosine deaminase 2 to inhibit growth of solid tumors. Cancer Res 2021;81:3319-32.

193 Oh MS, Guzner A, Wainwright DA, et al. The impact of beta blockers on survival outcomes in patients with non-small-cell lung cancer treated with immune checkpoint inhibitors. Clin Lung Cancer 2021;22:e57-62.

194 Cortellini A, Tucci M, Adamo V, et al. Integrated analysis of concomitant medications and oncological outcomes from PD-1/PDL1 checkpoint inhibitors in clinical practice. J Immunother Cancer 2020;8:e001361.

195 Duan B, Davis R, Sadat EL, et al. Distinct roles of adenylyl cyclase $\mathrm{VII}$ in regulating the immune responses in mice. $\mathrm{J}$ Immunol 2010;185:335-44

196 Cole SW, Sood AK. Molecular pathways: beta-adrenergic signaling in cancer. Clin Cancer Res 2012;18:1201-6.

197 Haldar R, Ricon-Becker I, Radin A, et al. Perioperative COX2 and $\beta$-adrenergic blockade improves biomarkers of tumor metastasis, immunity, and inflammation in colorectal cancer: A randomized controlled trial. Cancer 2020;126:3991-4001.

198 Vaithianathan R, Hockey PM, Moore TJ, et al. latrogenic effects of COX-2 inhibitors in the US population. Drug Safety 2009;32:335-43.

199 Pedersen L, Idorn M, Olofsson GH, et al. Voluntary running suppresses tumor growth through epinephrine- and IL-6dependent NK cell mobilization and redistribution. Cell Metab 2016;23:554-62.

200 Baratelli F, Lin Y, Zhu L, et al. Prostaglandin E2 induces FOXP3 gene expression and T regulatory cell function in human CD4+ T cells. $J$ Immunol 2005;175:1483-90.
201 Ackerman JE, Best KT, O'Keefe RJ, et al. Deletion of EP4 in S100a4-lineage cells reduces scar tissue formation during early but not later stages of tendon healing. Sci Rep 2017;7:8658.

202 Lee RK, Knapp S, Wurtman RJ. Prostaglandin E2 stimulates amyloid precursor protein gene expression: inhibition by immunosuppressants. J Neurosci 1999;19:940-7.

203 Simonson MS, Herman WH, Dunn MJ. PGE2 induces c-fos expression by a cAMP-independent mechanism in glomerular mesangial cells. Exp Cell Res 1994;215:137-44.

204 Allaire M-A, Dumais N. Involvement of the MAPK and RhoA/ROCK pathways in PGE2-mediated CCR7-dependent monocyte migration. Immunol Lett 2012;146:70-3.

205 Luan B, Yoon Y-S, Le Lay J, et al. CREB pathway links PGE2 signaling with macrophage polarization. Proc Natl Acad Sci U S A 2015;112:15642-7.

206 Chandrasekharan NV, Dai H, Roos KLT, et al. COX-3, a cyclooxygenase-1 variant inhibited by acetaminophen and other analgesic/antipyretic drugs: cloning, structure, and expression. Proc Natl Acad Sci U S A 2002;99:13926-31.

207 Oksuz E, Atalar F, Tanırverdi G, et al. Therapeutic potential of cyclooxygenase-3 inhibitors in the management of glioblastoma. $J$ Neurooncol 2016;126:271-8

208 Masoumi E, Jafarzadeh L, Mirzaei HR, et al. Genetic and pharmacological targeting of A2A receptor improves function of anti-mesothelin CAR T cells. J Exp Clin Cancer Res 2020;39:49.

209 Newick K, O'Brien S, Sun J, et al. Augmentation of car T-cell trafficking and antitumor efficacy by blocking protein kinase $\mathrm{A}$ localization. Cancer Immunol Res 2016;4:541-51.

210 Rafiq S, Hackett CS, Brentjens RJ. Engineering strategies to overcome the current roadblocks in car T cell therapy. Nat Rev Clin Oncol 2020;17:147-67.

211 Allard B, Pommey S, Smyth MJ, et al. Targeting CD73 enhances the antitumor activity of anti-PD-1 and anti-CTLA-4 mAbs. Clin Cancer Res 2013;19:5626-35.

212 Curran MA, Montalvo W, Yagita H, et al. PD-1 and CTLA-4 combination blockade expands infiltrating $T$ cells and reduces regulatory $T$ and myeloid cells within B16 melanoma tumors. Proc Natl Acad Sci U S A 2010;107:4275-80. 